ITMPR808.tex

Comments welcome

\title{
Inflation Targeting as a Monetary Policy Rule
}

\author{
Lars E.O. Svensson* \\ Institute for International Economic Studies, Stockholm University; \\ CEPR and NBER
}

First draft: May 1998

This version: August 1998

\begin{abstract}
The purpose of the paper is to survey and discuss inflation targeting in the context of monetary policy rules. The paper provides a general conceptual discussion of monetary policy rules, attempts to clarify the essential characteristics of inflation targeting, compares inflation targeting to other monetary policy rules, and draws some conclusions for the monetary policy of the European System of Central Banks.

JEL Classification: E42, E52
\end{abstract}

${ }^{*}$ This paper was prepared for the Sveriges Riksbank-IIES Conference on Monetary Policy Rules, held in Stockholm, June 12-13, 1998. I thank the conference participants and especially Alan Blinder, Jon Faust, Dale Henderson, Torsten Persson, Anders Vredin and Volker Wieland for comments, and Christina Lönnblad for secretarial and editorial assistance. Interpretations and any errors are my own responsibility. Email: Lars.Svensson@iies.su.se. Homepage: http://www.iies.su.se/leosven/. 


\section{Introduction}

The purpose of this paper is to survey and discuss inflation targeting in the context of monetary policy rules, to clarify the essential characteristics of inflation targeting, to compare inflation targeting to other monetary policy rules, and to draw some conclusions for the monetary policy of the European System of Central Banks (ESCB).

In section 2, I provide a general conceptual discussion of monetary policy rules, starting from the current conventional wisdom about the transmission mechanism. In particular, I distinguish between instrument rules and targeting rules. In section 3, I discuss the general characteristics of inflation targeting and argue that inflation targeting is a stronger commitment to a systematic and optimizing monetary policy than other monetary policy regimes. I discuss both the loss function that can be associated with inflation targeting and the corresponding operating procedure, "inflation-forecast targeting," that is, that inflation targeting can be interpreted as a targeting rule for a synthetic intermediate variable, namely a conditional inflation forecast. I also discuss the role of transparency in inflation targeting, as well as issues of model uncertainty and model robustness.

In section 4 , I use the general framework of section 2 to make a comparison with some other monetary policy strategies, namely money-growth targeting and nominal-GDP targeting. In section 5 , I draw some conclusions for the monetary policy of the ESCB. In section 6, I present some general conclusions.

Appendices A-D contain some technical details, including a method for constructing conditional forecasts for arbitrary reaction functions in forward-looking models (appendix A).

\section{Monetary policy rules}

One of the main points in this paper is the usefulness of distinguishing between instrument rules and targeting rules, for discussing monetary policy rules in general and for understanding inflation targeting in particular. To avoid misunderstandings, it also seems desirable to clearly define the definition of "targeting." In this paper, as in Rogoff [81], Walsh [108], Svensson [91] and [93], Cecchetti [21], Clarida, Gali and Gertler [25] and Rudebusch and Svensson [83], target variables are variables appearing in loss functions. In some of the literature, targets sometimes refer to variables in reaction functions. ${ }^{1}$ These definitions of targets and targeting are not equivalent. As shown in Svensson [94], it is usually inefficient to let the instrument respond to target variables, compared to letting the instrument respond to the determinants of the target variables.

In order to avoid ambiguity, this section outlines some central definitions for discussing monetary policy rules. To be concrete, the definitions to be used are presented within a linear model with a quadratic loss function. ${ }^{2}$

${ }^{1}$ For examples see, especially, Bryant, Hooper and Mann [19], chapter 1, but also Judd and Motley [57], McCallum [70] and Bernanke and Woodford [11].

2 The discussion extends the corresponding discussion in Rudebusch and Svensson [83] by using a model with forward-looking variables, by providing a general definition of monetary policy rules, by distinguishing reaction functions and rules, and by allowing for both explicit and implicit instrument rules. Thus, Rudebusch and Svensson [83] do not explicitly define reaction functions, and restrict instrument rules to be prescribed (explicit) reaction functions, whereas the current treatment allows instrument rules to be both explicit and implicit reaction functions. 


\subsection{The transmission mechanism}

Since the transmission mechanism for monetary policy is central to the discussion of monetary policy rules, this subsection starts by discussing the conventional wisdom concerning the transmission mechanism. This conventional wisdom appears to grow increasingly dominant. ${ }^{3}$

In a closed economy, standard transmission channels include an aggregate demand channel and an expectations channel. With the aggregate demand channel, monetary policy affects aggregate demand, with a lag, via its effect on the short real interest rate (and possibly on the availability of credit). ${ }^{4}$ Aggregate demand then affects inflation, with another lag, via an aggregate supply equation (a Phillips curve). The expectations channel allows monetary policy to affect inflation expectations which, in turn, affect inflation, with a lag, via wage- and price-setting behavior. Appendix C gives an example (from Svensson [96] and [93]) of a very simple model of the transmission mechanism for a closed economy, which abstracts from the expectations mechanism (or, alternatively, treats expectations as adaptive), where monetary policy affects aggregate demand with a one-year lag and inflation with a two-year lag. This example will frequently be used to illustrate some of the points below.

In an open economy, there are additional channels for the transmission of monetary policy. The exchange rate is affected by the difference between domestic and foreign nominal interest rates and expected future exchange rates, via an interest parity condition. With sticky prices, the nominal exchange rate affects the real exchange rate. The real exchange rate will affect the relative price between domestic and foreign goods, which, in turn, will affect both domestic and foreign demand for domestic goods, and hence contribute to the aggregate-demand channel for the transmission of monetary policy. There is also a direct exchange rate channel for the transmission of monetary policy to CPI inflation, in that the exchange rate affects domestic currency prices of imported final goods, which enter the CPI and hence CPI inflation. Typically, the lag of this direct exchange rate channel is considered to be shorter than that of the aggregate demand channel. Hence, monetary policy can affect CPI inflation with a shorter lag by inducing exchange rate movements. Finally, there is an additional exchange rate channel to inflation: The exchange rate will affect the domestic currency prices of imported intermediate inputs. Eventually, it will also affect nominal wages via the effect of the CPI on wage-setting. In both cases, it will affect the cost of domestically produced goods, and hence domestic inflation (inflation in the prices of domestically produced goods).

Appendix D gives an example (from Svensson [96]) of a relatively rich model of the transmission mechanism in a small open economy. The crucial building blocks are an aggregate supply equation (a Phillips curve) for domestic inflation, an aggregate demand equation for domestically produced goods and services, a real interest parity equation for the real exchange rate, and an equation defining CPI inflation as a weighted sum of domestic inflation and inflation in imported goods. Both aggregate supply and aggregate demand are derived with some microfoundations

\footnotetext{
${ }^{3}$ See Mishkin [75] and the contributions mentioned there. See Fuhrer and Moore [44], King and Wolman [62], Yun [113], McCallum and Nelson [72], Woodford [112], Rotemberg and Woodford [82], Goodfriend and King [45], and Clarida, Gali and Gertler [25] for building blocks, microfoundations and discussions of different versions of this conventional wisdom of the transformation mechanism for closed economies. Some contributions ignore control lags and persistence, though. Svensson [96] provides an open-economy extension.

More elaborate large models actually used by central banks include Bank of Canada's QPM model [28], Reserve Bank of New Zealand's Forecasting and Policy System [12], and the Federal Reserve Board's FRB/US model [18].

${ }_{4}^{4}$ The aggregate demand channel can be separated into an interest rate channel and a parallel credit channel. The latter is, for instance, discussed in Bernanke and Gertler [6].
} 
and forward-looking rational expectations. Domestic inflation depends on expected future inflation, the expected future output gap, and the expected future real exchange rate. Aggregate demand depends on an expected future long real interest rate (which, in turn, is affected by expected future short real interest rates) and the expected future real exchange rate. Monetary policy affects the exchange rate and the CPI in the current period, aggregate demand in one period, and domestic inflation in two periods. The relative lags are consistent with findings from VAR studies, for instance, Christiano, Eichenbaum and Evans [22], Bernanke and Mihov [8] and Cushman and Zha [31] (although some of the lags may actually be imposed as identifying restrictions).

In this view of the transmission mechanism, it is apparent that, perhaps somewhat paradoxically and heretically, money only plays a minor role. For instance, many models, including the central bank models mentioned in footnote 3, do not even specify a demand function for money, although such a demand function is easily introduced (see the discussion of money-growth targeting in section 4.1). Then, the central bank simply supplies whatever quantity of money that is demanded at the preferred level of the short interest rate. Money becomes an endogenous variable, as emphasized in Taylor [102] and [104] and, consistent with empirical findings, a high long-run correlation between the price level and money supply arises. Moreover, in the short and medium run, monetary aggregates in these models have little or no predictive power over other determinants of inflation. Thus, in the transmission mechanism, the focus is not on money supply growth but on the short nominal rate, the resulting short real rate and exchange rate, and the effects on expectations, aggregate demand, domestic inflation and CPI inflation.

\subsection{A fairly general linear model for monetary policy}

The different models of the conventional transmission mechanism described above (in particular the examples in appendices $\mathrm{C}$ and $\mathrm{D}$ ) can (as long as they are linear) be written as the following fairly general linear model of an economy,

$$
\left[\begin{array}{c}
X_{t+1} \\
x_{t+1 \mid t}
\end{array}\right]=A\left[\begin{array}{c}
X_{t} \\
x_{t}
\end{array}\right]+B i_{t}+\left[\begin{array}{c}
v_{t+1} \\
0
\end{array}\right]
$$

where $X_{t}$ is a column vector of $n_{1}$ predetermined variables (state variables), $x_{t}$ is a column vector of $n_{2}$ forward-looking variables (non-predetermined variables), $i_{t}$ is a column vector of $n_{i}$ central bank instruments (control variables), $v_{t+1}$ is a column vector of $n_{1}$ exogenous iid shocks with zero means and a constant covariance matrix $\Sigma_{v v}$, and $A$ and $B$ are matrices of appropriate dimensions. In order to include the possibility that the variables may have non-zero means, it is understood that the first element of $X_{t}$ is unity and that corresponding means are incorporated in the first column of $A .{ }^{5} 6$

At the beginning of period $t, v_{t}$ and $X_{t}$ are realized. Then, $i_{t}$ is set by the central bank. Finally, $x_{t}$ results, and period $t$ ends. Each variable is observable. Although the information set

\footnotetext{
${ }^{5}$ The predetermined variables $X_{t}$ depend on exogenous shocks in period $t$ and on lagged variables (predetermined, forward-looking, instruments). This definition is consistent with Klein [63], that is, that predetermined variables have exogenous one-period-ahead forecast errors. The forward-looking variables $x_{t}$ depend on the predetermined variables in period $t$, the instruments in period $t$, and the expectations in period $t$ of future forward-looking variables.

${ }^{6}$ One generalization is when $B i_{t}$ is replaced by $\Sigma_{\tau=0}^{T} B^{\tau} i_{t+\tau \mid t}$. See Svensson [96] and appendix D for an example with $T=1$. Another generalization is when the left side is premultiplied by a singular matrix.
} 
at the beginning of period $t$ is $\left\{v_{t}, X_{t}, v_{t-1}, X_{t-1}, i_{t-1}, \ldots\right\}, X_{t}$ is a sufficient statistic, that is, a state variable, at the beginning of period $t$. Hence, $X_{t}$ comprises the indicators at the beginning of the period, that is, the prices and quantities conveying information to the central bank. The expression $x_{t+1 \mid t}$ denotes $\mathrm{E}_{t} x_{t+1}$, the expectation of $x_{t+1}$ conditional upon information available at the end of period $t$ (that is, $X_{t}, i_{t}$ and $\left.x_{t}\right) .^{7}$

Furthermore, let $Y_{t}$ be a column vector of $n_{3}$ target variables, given by

$$
Y_{t}=C\left[\begin{array}{c}
X_{t} \\
x_{t}
\end{array}\right]+D i_{t}
$$

where $C$ and $D$ are matrices of appropriate dimension. (Intermediate target variables are discussed below.) Let $\hat{Y}$ be a column vector of $n_{3}$ target levels. ${ }^{8}$ For a given positive-definite $n_{3} \times n_{3}$ weight matrix $K$, let the period loss function, $L_{t}$, be the quadratic form

$$
L_{t}=\left(Y_{t}-\hat{Y}\right)^{\prime} K\left(Y_{t}-\hat{Y}\right),
$$

(where' denotes the transpose) and, for a given discount factor $\delta(0<\delta<1)$, let the intertemporal loss function be

$$
\mathrm{E}_{t}(1-\delta) \sum_{\tau=0}^{\infty} \delta^{\tau} L_{t+\tau}
$$

For $\delta=1$, the intertemporal loss function (2.4) can be interpreted as the unconditional mean of the period loss function,

$$
\mathrm{E}\left[L_{t}\right]=\mathrm{E}\left[\left(Y_{t}-\hat{Y}\right)^{\prime} K\left(Y_{t}-\hat{Y}\right)\right] .
$$

An unambiguous definition of a reaction function is convenient. Let a(n explicit) reaction function be a single-valued mapping from the predetermined variables to the instruments. Thus, a linear reaction function can be written

$$
i_{t}=f X_{t}
$$

where $f$ is an $n_{i} \times n_{1}$ matrix. The elements of $f$ can be called response coefficients.

In a commitment equilibrium for a given linear policy rule, the model (2.1) is solved with (2.6) for a given $f$. The forward-looking variables will be an endogenous linear function of the state variables,

$$
x_{t}=H X_{t},
$$

where the matrix $H$ depends on $A, B$ and $f .{ }^{9}$ The dynamics will then be given by

$$
\begin{aligned}
x_{t} & =H X_{t} \\
Y_{t} & =\left(C_{1}+C_{2} H+D f\right) X_{t} \\
X_{t+1} & =G_{11} X_{t}+v_{t+1},
\end{aligned}
$$

where the matrix $G$ is given by

$$
G=A+B\left[\begin{array}{ll}
f & 0_{n_{i} \times n_{2}}
\end{array}\right],
$$

\footnotetext{
${ }^{7}$ Thus, this formulation abstracts from non-linearity, model uncertainty, unobservable variables, and private information.

${ }^{8}$ The target levels may be time-dependent, $\hat{Y}_{t}$.

${ }^{9}$ See Blanchard and Kahn [15], King and Watson [61], Klein [63] and Sims [87] for different solution algorithms.
} 
where $0_{n_{i} \times n_{2}}$ denotes an $n_{i} \times n_{2}$ matrix of zeros, and the matrices $C$ and $G$ are decomposed according to $X_{t}$ and $x_{t}$,

$$
C=\left[\begin{array}{l}
C_{1} \\
C_{2}
\end{array}\right], G=\left[\begin{array}{ll}
G_{11} & G_{12} \\
G_{21} & G_{22}
\end{array}\right] .
$$

If the instruments depend on both the predetermined variables and the forward-looking variables, we have an implicit reaction function, for instance,

$$
i_{t}=f X_{t}+g x_{t}
$$

where $g$ is a matrix of appropriate dimension. In order to find the (explicit) reaction function, that is, to express the instruments as a function of predetermined variables only, the model (2.1) must be solved with the restriction (2.11), for given $f$ and $g$. If a solution exists, the forwardlooking variables will fulfill (2.7) (where the matrix $H$ depends on $f$ and $g$ ), and in equilibrium, the instruments will obey the reaction function

$$
i_{t}=(f+g H) X_{t}
$$

In a discretion equilibrium, ${ }^{10}$ the central bank minimizes (2.4) in each period $t$, subject to $X_{t}$, (2.1), (2.2), and the knowledge that the policy in period $t+1$ will be the result of reoptimization in period $t+1$. The optimal reaction function under discretion will be linear and will be denoted

$$
i_{t}=\hat{f} X_{t}
$$

As in (2.7), the forward-looking variables will in equilibrium be a linear function of the predetermined variables.

\subsection{Monetary policy rules}

What is a monetary policy rule? I will interpret "rule" in a fairly broad sense, namely "a prescribed guide for conduct or action," which is the first definition given in Merriam-Webster [74]. Accordingly, I define a monetary policy rule as a prescribed guide for monetary policy conduct.

As mentioned above, I find it useful to distinguish between two kinds of monetary policy rules, namely instrument rules and target(ing) rules.

\subsubsection{Instrument rules}

Instrument rules are the monetary policy rules most frequently referred to in the literature and they are what is frequently meant by "rules". ${ }^{11}$ An instrument rule expresses the instruments as a prescribed function of predetermined or forward-looking variables, or both. If the instruments are a prescribed function of predetermined variables only, that is, a prescribed reaction function, the rule is an explicit instrument rule. If the instruments are a prescribed function of forward-looking variables, that is, a prescribed implicit reaction function, the rule is an implicit

\footnotetext{
${ }^{10}$ See Oudiz and Sachs [78], Backus and Driffill [2], Curry and Levine [30], Blake and Westaway [14] and Svensson [89] for further discussions of discretion and commitment equilibria with forward-looking variables.

${ }^{11}$ For instance, these are the kind of rules discussed by Taylor [104].
} 
instrument rule. In the latter case, the instrument rule is an equilibrium condition (there are nontrivial endogenous variables on both sides of the equation describing the instrument rule).

Thus, a linear explicit instrument rule in the above model can be written as (2.6), where $f$ is prescribed. Similarly, a linear implicit instrument rule can be written as (2.11), where $f$ and $g$ are prescribed. A simple instrument rule has few arguments; that is, it depends on few predetermined or forward-looking variables.

A well-known example of a simple instrument rule is the Taylor rule [100],

$$
i_{t}=\bar{i}+1.5\left(\pi_{t}-2\right)+0.5 y_{t}
$$

where $i_{t}$ is the federal funds rate in quarter $t, \bar{i}$ is the average federal funds rate (4 percent in [100]), $\pi_{t}$ is 4 -quarter inflation, $y_{t}$ is the output gap, and the federal funds rate responds to deviations of inflation from the 2 percent level and to the output gap with coefficients 1.5 and 0.5 , respectively. ${ }^{12}$ If $y_{t}$ and $\pi_{t}$ are predetermined in period $t$, the Taylor rule is an explicit instrument rule; if they are forward-looking in period $t$ the Taylor rule is an implicit instrument rule, that is, an equilibrium condition. A second example is the Henderson-McKibbin [53], [54] rule,

$$
i_{t}=\bar{i}+2\left(\pi_{t}+y_{t}-\widehat{\pi+y}\right),
$$

where $\gamma>0, \bar{i}$ is the average federal funds rate, and the federal funds rate responds to deviations between the sum of inflation and output from the "target" level $\widehat{\pi+y}$. Again, whether it is an explicit or implicit rule depends on whether $\pi_{t}$ and $y_{t}$ are predetermined or forward-looking. A third example is McCallum's [69] rule for the (log) monetary base, $b_{t}$,

$$
b_{t}-b_{t-1}=\widehat{\Delta x}+\frac{1}{16}\left[\left(b_{t-1}-x_{t-1}\right)-\left(b_{t-17}-x_{t-17}\right)\right]-\alpha\left(x_{t-1}-\hat{x}_{t-1}\right),
$$

where $\alpha>0, x_{t}$ is $(\log )$ nominal GDP in quarter $t, \widehat{\Delta x}$ is a target for nominal GDP growth, and $\hat{x}_{t}=\hat{x}_{t-1}+\widehat{\Delta x}$ is a corresponding target path for the level. In this explicit instrument rule, the growth rate of the monetary base responds to deviations of nominal GDP from the target path and to changes in the income velocity of the base. ${ }^{13}$

An example of an implicit reaction function is the one used in Bank of Canada's QPM model [28] and in Reserve Bank of New Zealand's Forecasting and Policy System [12],

$$
i_{t}=i_{t}^{L}+\gamma\left(\pi_{t+T \mid t}-\hat{\pi}\right)
$$

where $i_{t}$ is a short nominal interest rate, $i_{t}^{L}$ is a long nominal interest rate, $\pi_{t+T \mid t}$ is a $T$-quarterahead "rule-consistent inflation forecast" (a $T$-quarter-ahead inflation forecast conditional upon the model and the implicit instrument rule (2.15); $T$ is usually $6-8$ quarters), $\hat{\pi}$ is the midpoint

${ }^{12}$ The Taylor rule is often equivalently written

$$
i_{t}=\bar{r}+\pi_{t}+0.5\left(\pi_{t}-\hat{\pi}\right)+0.5 y_{t},
$$

where $\bar{r}$ is the average real rate (2 percent in [100]) and $\hat{\pi}$ is average inflation (or an inflation target).

13 McCallum has emphasized that in order to be operational, a monetary policy rule should only rely on information explicitly available at the time when the instrument is set, and which takes the fact that quarterly GDP and the GDP deflator are reported with a lag into account. Therefore, his rule explicitly uses nominal GDP data from the last quarter. Alternatively, the arguments of instrument rules can be forecasts of current variables, say $\pi_{t \mid t-1}$ and $y_{t \mid t-1}$ for the Taylor rule. This presents no operational difficulty, although it clearly makes it more difficult for outsiders to verify whether the rule is obeyed. 
of the inflation target range, and $\gamma>0$. That is, the instrument $i_{t}$ is adjusted such that the (reverse) slope of the yield curve, $i_{t}-i_{t}^{L}$, is proportional to the deviation of the rule-consistent inflation forecast from the inflation target. This is an example of an implicit reaction function, since both the long interest rate and the inflation forecast are forward-looking and depend on the reaction function itself. ${ }^{14}$

A variant of (2.15),

$$
i_{t}=\bar{i}+\gamma\left(\pi_{t+T \mid t}-\hat{\pi}\right),
$$

where the instrument responds directly to deviations of the rule-consistent inflation forecast from the inflation target, is discussed in Haldane [49], and further examined in Haldane and Batini [50] and Rudebusch and Svensson [83]. These implicit reaction functions would be examples of implicit instrument rules, if they were prescribed guides for monetary policy.

The implicit reaction functions (2.15) and (2.16) are simple, in the sense that few forwardlooking variables enter on the right-hand side. However, the corresponding equilibrium (explicit) reaction functions (2.12) resulting when the model is solved are complex, in that they depend on all the predetermined variables that determine the inflation forecast and, for (2.15), the long interest rate, and in that the response coefficients are complex functions of the parameters of the model and the implicit reaction function.

From equation (C.13) in appendix C (following Svensson [91], equation (6.10)), it is apparent that implicit reaction functions of the form (2.16) are generally not optimal, in spite of their being used by Bank of Canada and Reserve Bank of New Zealand, since other variables, for instance output, contain is additional useful information, beyond what is contained in the inflation forecast. This is also the case for strict inflation targeting, when only inflation enter the loss function. It is also demonstrated numerically in Haldane and Batini [50] and Rudebusch and Svensson [83] that (2.16) is generally not optimal.

\subsubsection{The role of instrument rules}

What is generally the role of instrument rules in monetary policy? In practice, no central bank follows an instrument rule, either explicit or implicit. Every central bank uses more information than the frequently suggested simple rules rely on, especially in open economies. In particular, no central bank reacts in a prescribed mechanical way to a prescribed information set. As is known by every student of modern central banking, the bank's Board or Monetary Policy Committee reconsiders its monetary policy decisions more or less from scratch at frequent intervals, by taking all the relevant information into account (with the possible exception of a fixed exchange rate). The bank frequently reconsiders (and, at best, reoptimizes); rather than considers (and, at best, optimizes) once and for all, and then simply applies the resulting reaction function forever after. This reconsideration of the bank's decisions means that the situation is best described as decision-making under discretion rather than commitment; there will inevitably be reconsiderations and new decisions in the future, and there is in practice no commitment mechanism to prevent this. ${ }^{15}$

\footnotetext{
${ }^{14}$ The reaction function is also used in Black, Macklem and Rose [13]. Implicit reaction functions are problematic, in that nonexistence or multiplicity of equilibria can occur, which has been demonstrated by Woodford [111] and Bernanke and Woodford [11].

${ }_{15}$ Although one might conceive of a law mandating the central bank to follow a simple instrument rule, such an instrument rule would have to be so exceedingly simple in order to be verifiable, that it would be manifestly
} 
Therefore, the role of simple or complex instrument rules is, in practice, never to commit the banks. Instead, they serve as base-lines, that is, as comparisons and frames of reference, for the actual policy and its evaluation. In contrast, targeting rules, as in Rogoff [81], Walsh [108], Svensson [91] and [93], Cecchetti [21], Clarida, Gali and Gertler [25], and Rudebusch and Svensson [83], have the potential to serve as a kind of commitment (namely a commitment to a loss function, although it is still minimized under discretion), and are potentially closer to the actual practice and decision framework of (at least) inflation-targeting central banks.

\subsubsection{Targeting rules}

By a targeting rule, I mean, at the most general level, the assignment of a particular loss function to be minimized. More precisely, a target(ing) rule specifies a (vector of) target variable(s) $Y_{t}$, a (vector of) target level(s) $\hat{Y}$, and a corresponding loss function (2.3) and (2.4) (that is, a weight matrix $K$ and a discount factor $\delta$ ) that is to be minimized. ${ }^{16}$

At a more specific level, a targeting rule can be expressed as an equation (a system of equations) that the targets variables must fulfill. Consider the special case when (1) the central bank has perfect control over the goal variables and (2) there is no intratemporal or intertemporal tradeoff between the goal variables. ${ }^{17}$ Then, there is a trivial first-order condition for a minimum of the loss function,

$$
Y_{t}=\hat{Y}
$$

In this case, the targeting rule can equivalently be expressed as an equation which must be fulfilled by the target variables.

When the central bank has imperfect control over the target variables, and as long as there is no intratemporal or intertemporal tradeoff between the goal variables, the first-order condition is still trivial,

$$
Y_{t+\tau \mid t}=\hat{Y}
$$

for $\tau \geq T$, where $Y_{t+\tau \mid t}$ denotes a conditional forecast of $Y_{t+\tau}$ (to be defined below) and $T \geq 0$ is the shortest horizon at which the instrument has an effect on the goal variables.

For the realistic case with imperfectly controlled target variables for which there is an intertemporal or intratemporal tradeoff, the situation is more complex. However, the targeting rule can still be expressed as a system of equations representing a first-order condition for a minimum of the loss function.

To show this, it is necessary to provide a more rigorous definition of conditional forecasts. More precisely, for a fixed period $t$, let $X_{t+\tau \mid t}, x_{t+\tau \mid t}, Y_{t+\tau \mid t}$ and $i_{t+\tau \mid t}$ for $\tau \geq 0$ denote predetermined variables, forward-looking variables, and target variables and instrument settings, respectively, in period $t+\tau$, for the corresponding deterministic model (2.1) when the shocks after period $t$ are all zero $\left(v_{t+\tau}=0\right.$ for $\left.\tau \geq 1\right)$. For any variable $\xi$, let $\xi^{t}$ denote the future path $\xi_{t}, \xi_{t+1 \mid t}, \xi_{t+2 \mid t}, \ldots$ Since the model is linear and the shocks are additive, we realize that these paths can also be interpreted as conditionally expected paths, expected values of future

inefficient in many circumstances and therefore likely to be strongly resisted by both legislators and central bankers.

${ }^{16}$ The target levels can be time-dependent, $\hat{Y}_{t}$.

${ }^{17}$ The latter generally requires as many linearly independent instruments as there are target variables. Hence, if there is only one instrument, there must be only one target variable. 
random variables, conditional on the information available in period $t$ (that is, $X_{t}$, the model (2.1) and (2.2), and the zero means of the shocks). This is why they can be called conditional forecasts. ${ }^{18}$ More precisely, consider the set $\mathcal{I}_{t}$ of paths $i^{t}$ of instrument settings, for which there exist bounded paths $X^{t}, x^{t}$ and $Y^{t}$ of predetermined, forward-looking and target variables, respectively. For each $i^{t} \in \mathcal{I}_{t}$, let $\xi^{t}\left(i_{t}\right)$ denote the corresponding path for variable $\xi=X, x$ and $Y$, and call it the corresponding conditional forecast (conditional on $X_{t}, i^{t},(2.1),(2.2)$, and $\mathrm{E}\left[v_{t+\tau}\right]=0, \tau \geq 1$.). Accordingly, the conditional forecast of target variables is denoted $Y^{t}\left(i^{t}\right)$. Finally, let

$$
\mathcal{Y}_{t} \equiv\left\{Y^{t}\left(i^{t}\right) \mid i^{t} \in \mathcal{I}_{t}\right\}
$$

denote the set of feasible conditional forecasts.

Constructing conditional forecasts in a backward-looking model (that is, a model without forward-looking variables) is straightforward. Constructing such forecasts in a forward-looking model raises some specific difficulties, which are explained and resolved in appendix A.

Due to the certainty-equivalence that holds in a linear model with a quadratic loss function and additive shocks, it is now apparent that the stochastic optimization problem to minimize the expected loss function over future random target variables (2.4), subject to (2.1) and (2.2), is equivalent to the deterministic problem to minimize the deterministic loss function over the deterministic paths of conditional forecasts of the target variables $Y^{t}$,

$$
\sum_{\tau=0}^{\infty} \delta^{\tau}\left(Y_{t+\tau \mid t}-\hat{Y}\right)^{\prime} K\left(Y_{t+\tau \mid t}-\hat{Y}\right)
$$

subject to

$$
Y^{t} \in \mathcal{Y}_{t}
$$

The first-order condition for a minimum of (2.18) subject to (2.19) can be written as the system of equations

$$
G_{t}\left(Y_{t}, Y_{t+1 \mid t}, Y_{t+2 \mid t}, \ldots\right)=0
$$

which the conditional forecasts of the target variables must fulfill (see appendix B for details). Thus, the targeting rule for target variables under incomplete control can be formulated as the system of equations (2.20) for the conditional forecasts.

A targeting rule in a given model implies a particular reaction function, in the sense that the first-order conditions (2.17) or (2.20) can be interpreted as an implicit reaction function, in the following way. Let $Y^{t}$ be the solution to the first-order condition, and let $i^{t}=i_{t}, i_{t+1 \mid t}, \ldots$, be the corresponding instrument path. The first element, $i_{t}$, gives the instrument setting for period $t$. Obviously, it will be a function of the predetermined variables, $X_{t}$, in this period. In a linear model with a quadratic loss function, it will be a linear function of $X_{t}$, and the corresponding (explicit) reaction function can be written as (2.6).

\subsubsection{Intermediate-targeting rules}

An intermediate-targeting rule specifies an (a vector of) intermediate target variable(s), $Z_{t}$, given by

$$
Z_{t}=C_{Z}\left[\begin{array}{c}
X_{t} \\
x_{t}
\end{array}\right]+D_{Z} i_{t}
$$

\footnotetext{
${ }^{18}$ Alternatively, they can be called "projections," as in the publications of the Reserve Bank of New Zealand.
} 
where $C_{Z}$ and $D_{Z}$ are matrices of appropriate dimensions, a target level (vector), $\hat{Z}_{t}$, and an intermediate (intertemporal) loss function to be minimized,

$$
\mathrm{E}_{t}(1-\delta) \sum_{\tau=0}^{\infty} \delta^{\tau}\left(Z_{t+\tau}-\hat{Z}_{t+\tau}\right)^{\prime} K_{Z}\left(Z_{t+\tau}-\hat{Z}_{t+\tau}\right)
$$

where $K_{Z}$ is a positive-definite weight matrix of appropriate dimension.

An "ideal" intermediate target variable is highly correlated with the goal, easier to control than the goal, easier to observe than the goal, and transparent (for instance in the sense of simplifying communication between the central bank and the general public as well as public understanding of monetary policy) (cf. the discussion in Svensson [91]). Then, the appropriate intermediate-targeting rule is efficient in minimizing the loss function (2.4). For instance, suppose that the intermediate target variables $Z_{t+\tau, t}$ in period $t$ predict the goal variables in period $t+\tau$ according to

$$
Y_{t+\tau}=M Z_{t+\tau, t}+\varepsilon_{Z, t+\tau}
$$

where $\varepsilon_{Z, t+\tau}$ is an iid shock with zero mean which is uncorrelated with $Z_{t+\tau, t}$ and $M$ is a given matrix of appropriate dimension. Let the intermediate target level $\hat{Z}$ fulfill

$$
\hat{Y}=M \hat{Z} \text {. }
$$

Then we have

$$
\begin{aligned}
\left(Y_{t+\tau}-\hat{Y}\right)^{\prime} K\left(Y_{t+\tau}-\hat{Y}\right) & =\left(Z_{t+\tau, t}-\hat{Z}\right)^{\prime} M^{\prime} K M\left(Z_{t+\tau, t}-\hat{Z}\right)+\varepsilon_{Z, t+\tau}^{\prime} K \varepsilon_{Z, t+\tau} \\
& \equiv\left(Z_{t+\tau, t}-\hat{Z}\right)^{\prime} K_{Z}\left(Z_{t+\tau, t}-\hat{Z}\right)+\varepsilon_{Z, t+\tau}^{\prime} K \varepsilon_{Z, t+\tau}
\end{aligned}
$$

where

$$
K_{Z} \equiv M^{\prime} K M
$$

Since the last term on the right side of (2.23) is exogenous, we realize that minimizing (2.21) with $\hat{Z}$ and $K_{Z}$ given by (2.23) and (2.24) will be equivalent to minimizing (2.4).

Intuitively, an intermediate-targeting rule will be optimal if the instruments only affect the target variables via the intermediate target variables, schematically illustrated as

$$
i_{t} \rightarrow Z_{t+T, t} \rightarrow Y_{t+\tau}
$$

for $0 \leq T \leq \tau$.

In general, the monetary transmission mechanism is too complex, with too many channels with different relative lags, for an intermediate variable to exist (except the "canonical" intermediate variables to be discussed next).

\subsubsection{The canonical intermediate target}

We immediately realize that a natural and optimal intermediate target, the "canonical" intermediate target, arises if the intermediate target variables $Z_{t+\tau, t}$ are identified with the conditional forecast of the target variables $Y_{t+\tau \mid t}$, the intermediate target levels $\hat{Z}_{t+\tau, t}$ with the target levels 
$\hat{Y}$, and the intermediate weight matrix $K_{Z}$ with the weight matrix $K$ (that is, the matrix $M$ above is the identity matrix)

$$
\begin{aligned}
Z_{t+\tau, t} & \equiv Y_{t+\tau \mid t} \\
\hat{Z}_{t+\tau, t} & \equiv \hat{Y} \\
K_{Z} & \equiv K .
\end{aligned}
$$

This intermediate-targeting rule obviously leads to the same equilibrium as the original targeting rule.

Thus, it appears that using conditional forecasts as intermediate target variables is optimal. In this case, the intermediate target variables are synthetic; they are theoretical constructions. Whether conditional forecasts are ideal intermediate targets depends on their being easily observed and transparent, an issue that I shall return to in the discussion of inflation targeting in section 3 .

\subsubsection{An example of a targeting rule}

In Svensson [91], a simple backward-looking model (that is, there are no forward-looking variables $x_{t}$ in (2.1)) is presented, where the first two elements of the vector of predetermined variables are inflation, $\pi_{t}$, and the output-gap, $y_{t}$ (see appendix $\mathrm{C}$ ). The instrument, a short interest rate, $i_{t}$, affects the output gap with a one-period control lag, and inflation with a twoperiod control lag. The target variables are also inflation and the output gap, and the period loss function is

$$
L_{t}=\frac{1}{2}\left[\left(\pi_{t}-\hat{\pi}\right)^{2}+\lambda y_{t}^{2}\right]
$$

where $\lambda \geq 0$ is the relative weight on output-gap stabilization. Hence, the vector of target variables is $Y_{t}=\left(\pi_{t}, y_{t}\right)^{\prime}$, with target levels $\hat{Y}=(\hat{\pi}, 0)^{\prime}$ and a diagonal weight matrix $K$ with diagonal $\frac{1}{2}(1, \lambda)$.

The first-order condition can be written in several different ways. One is

$$
\pi_{t+2 \mid t}-\hat{\pi}=c(\lambda)\left(\pi_{t+1 \mid t}-\hat{\pi}\right),
$$

where the coefficient $c(\lambda) \geq 0$ is increasing in $\lambda$, with $c(0)=0$ and $\lim _{\lambda \rightarrow \infty} c(\lambda)=1$, the oneperiod-ahead conditional inflation forecast $\pi_{t+1 \mid t}$ is predetermined, and the two-period-ahead conditional inflation forecast $\pi_{t+2 \mid t}$ depends on the predetermined variables and the instrument in period $t$. Thus, the targeting rule can be formulated as "adjust the instrument such that the deviation of the two-year-ahead conditional inflation forecast from the inflation target is a fraction $c(\lambda)$ of the same deviation of the one-year-ahead forecast."

Alternatively, the targeting rule can be expressed as an intermediate-targeting rule. Let the intermediate-target variable in period $t$ be the two-period-ahead conditional inflation forecast, $Z_{t} \equiv \pi_{t+2 \mid t}$, and let the intermediate-target level be time-dependent and fulfill

$$
\hat{Z}_{t} \equiv \hat{\pi}+c(\lambda)\left(\pi_{t+1 \mid t}-\hat{\pi}\right) .
$$

Then, the same equilibrium can be reached with an intermediate-targeting rule with the intermediate loss function

$$
\frac{1}{2}\left(Z_{t}-\hat{Z}_{t}\right)^{2}
$$


or, equivalently, with the intermediate target fulfilling the first-order condition

$$
Z_{t}=\hat{Z}_{t}
$$

Appendix C shows several other ways of expressing the targeting and intermediate-targeting rules for this example and derives the corresponding reaction function.

\subsection{Some confusing terminology}

In the taxonomy outlined above, target variables are variables that appear in the loss function, while the variables that appear in the reaction function are indicators, predetermined variables (that cause and/or predict the target variables and therefore convey information). This terminology seems logical and consistent to me.

In the literature, "targeting variable $Y_{t}$ " or "having a target $\hat{Y}$ for variable $Y_{t}$ " sometimes implicitly or explicitly refers to a situation with a reaction function that is restricted in a particular way. ${ }^{19}$ Thus, the instrument is restricted to only respond to deviations between the target variable and the target level (and possibly to lagged instrument levels, to incorporate instrument smoothing), for instance,

$$
i_{t}=\bar{i}+g\left(Y_{t}-\hat{Y}\right)
$$

or

$$
i_{t}=(1-\rho) \bar{i}+\rho i_{t-1}+g\left(Y_{t}-\hat{Y}\right) .
$$

I find this use of the term "targeting" confusing and misleading, for several reasons. First, it is simply unrealistic. "Inflation targeting" in the real world does not correspond to central banks having reaction functions of the form

$$
i_{t}=\bar{i}+g\left(\pi_{t}-\hat{\pi}\right)
$$

Inflation-targeting central banks simply use much more information when setting their instrument than only the deviation of current inflation from the inflation target. ${ }^{20}$

Second, reaction functions of the form (2.26) or (2.27), where the instrument responds only to the deviation of a target variable from its target level, are generally inefficient, in the sense that they do not minimize relevant loss functions. Even though they may succeed in making the mean of the target variable equal to the target level, they generally lead to high variability in the target variable compared to other reaction functions. For instance, in Rudebusch and Svensson [83], the reaction function (2.28) preforms so badly in stabilizing inflation and output that we do not even report its results. It follows that any central bank trying to implement a reaction function like (2.26) or (2.27) would have strong incentives to deviate from it; the reaction function is not incentive-compatible.

Third, I find the above use of the term misleading, because a moment's thought makes it obvious that the appropriate policy is for the instrument to respond to the determinants of the

\footnotetext{
${ }^{19}$ For examples, see, especially, Bryant, Hooper and Mann [19], chapter 1, but also Judd and Motley [57], McCallum [70] and Bernanke and Woodford [11].

${ }_{20}$ For reasons explained at the end of section 2.3.1, inflation targeting in the real world does hardly imply $i_{t}=\bar{i}+g\left(\pi_{t+T \mid t}-\hat{\pi}\right)$ either.
} 
target variables, the indicators that cause or predict the target variables, rather than to respond to the target variables themselves (see Svensson [94] for further discussion and a few examples). This is, obviously, the reason why reaction functions of the form (2.26) and (2.27) are inefficient in stabilizing target variables around their target levels. Normally, target variables and indicator variables do not coincide. For instance, as shown in Svensson [91] and [93], even under strict inflation targeting (when the central bank is only concerned with stabilizing inflation around the inflation target), it is best for the central bank to respond to both inflation and output, since both are useful for predicting future inflation. Similarly, as discussed in Svensson [94], if the central bank wants to stabilize nominal GDP growth around a target growth rate, it is better to respond separately to the determinants of nominal GDP growth than just to respond to the deviation between nominal GDP growth and the target growth rate. Or, if the central bank wants to stabilize M3 growth around a target growth rate, it is better to respond to the determinants of M3 growth rather than to just respond to the deviation of M3 growth from the target growth rate (see section 4.1 below). ${ }^{21}$

Generally, what is in the loss function is generally not what is best to respond to, and what is best to respond to need not be in the loss function. It therefore seems better to describe the reaction function (2.26) more neutrally as "responding to $Y_{t}-\hat{Y}$ " than as "targeting $Y_{t} . " 22$

\section{Inflation targeting}

The main points in this section are the following: First, real-world inflation targeting can be interpreted as a targeting rule, with a relatively explicit loss function to be minimized. Uncontroversially (by now), this loss function also contains concerns about the stability of the real economy, for instance, output variability. That is, it corresponds to "flexible" rather than "strict" inflation targeting. Second, the targeting rule can also be expressed as an intermediatetargeting rule, which I shall call "inflation-forecast targeting" (although arguably a more precise but somewhat clumsy name would be "inflation-forecast-and-output-gap-forecast targeting"). Then the conditional inflation forecast is an intermediate target variable (or both the conditional inflation and output-gap forecast are intermediate target variables). Third, inflation targeting appears to be a commitment to a systematic and rational (that is, optimizing for the given loss function) monetary policy to a greater extent than any other monetary policy regime so far. This is because the operating procedure under inflation targeting, inflation-forecast targeting, can be interpreted as a way of ensuring that first-order conditions for a minimum of the loss function are (approximately) fulfilled. Also, the high degree of transparency and accountability associated with inflation targeting allows outsiders to monitor that those first-order conditions are fulfilled and creates strong incentives for the central bank not to deviate.

\subsection{Characteristics}

During the 1990's, New Zealand, Canada, U.K., Sweden and Australia have shifted to a new monetary policy regime, inflation targeting. ${ }^{23}$ This regime is characterized by

\footnotetext{
${ }^{21}$ It is optimal to respond only to lagged values of the target variables and to the instrument only in the special case when the target variables depend only on lags of themselves and the instrument.

${ }^{22}$ For a defense of "targeting $Y_{t}$," see McCallum and Nelson [73], appendix A.

23 Finland and Spain also have an explicit inflation target. However, since they participate in ERM, they also have an exchange rate target. Since both countries have been very anxious to qualify for membership in the EMU,
} 
1. an explicit quantitative inflation target,

2. an operating procedure, inflation-forecast targeting, which uses an internal conditional inflation forecast as an intermediate target variable,

3. a high degree of transparency and accountability. ${ }^{24}$

The explicit inflation target is either in the form of an interval or a point target, where the center of the interval or the point target currently varies across countries from 1.5 to 2.5 percent. The target refers to the Consumer Price Index or a variant of this that excludes some transitory components. For instance, mortgage costs or credit services may be excluded (to eliminate contradictory short-run effects of monetary policy on the CPI), or taxes and subsidies (to eliminate short-run effects of fiscal policy). Alternatively, a list of factors to be disregarded in the evaluation of monetary policy may be specified in advance.

The remaining part of this section discusses the loss function under inflation targeting, the operating procedure (inflation-forecast targeting), transparency and, finally, issues related to model uncertainty and model-robustness.

\subsection{The loss function}

Which loss function is then associated with inflation targeting? As reported below, there seems to be considerable agreement among academics and central bankers that the loss function is of the conventional form

$$
L_{t}=\frac{1}{2}\left[\left(\pi_{t}-\hat{\pi}\right)^{2}+\lambda y_{t}^{2}\right],
$$

where $\pi_{t}$ is the inflation in period $t, \hat{\pi}$ is the inflation target (or the midpoint of the target range) ${ }^{25} y_{t}$ is the output gap, and $\lambda \geq 0$ is the relative weights on stabilizing the output gap. In terms of the general framework in section 2, the vector of target variables is given by $Y_{t}=\left(\pi_{t}, y_{t}\right)^{\prime}$, the vector of target levels is given by $\hat{Y}=(\hat{\pi}, 0)^{\prime}$, and the weight matrix $K$ is the diagonal matrix with the diagonal $\frac{1}{2}(1, \lambda)$. As in Svensson [93] and [96], the case when $\lambda=0$ and only inflation enters the loss function is called strict inflation targeting, whereas the case when $\lambda>0$ and the output gap (or concern about stability of the real economy in general) enters the loss function is called flexible inflation targeting. ${ }^{26}$

Inflation targeting obviously always involves an attempt to minimize deviations of inflation from the explicit inflation target, corresponding to the first term in (3.1). Whereas there may previously have been some controversy about whether inflation targeting involves concern about real variability, represented by output-gap variability and corresponding to the second term in (3.1), there is now considerable agreement in the literature that this is indeed the case. Inflation targeting central banks are not what King [60] called "inflation nutters." For instance, Fischer

it is likely that the exchange rate target would receive priority if a conflict between the inflation target and the exchange rate target were to arise.

24 The rapidly increasing literature on inflation targeting includes the conference volumes Leiderman and Svensson [65], Haldane [47], Federal Reserve Bank of Kansas City [40], Lowe [67], and Macklem [68]. See also the surveys by Bernanke and Mishkin [10] and Bernanke, Laubach, Mishkin and Posen [7].

25 For a symmetric unimodal probability distribution, the probability of falling within the target range is maximized if the mean is set equal to the midpoint of target range. This provides some rationale for selecting the midpoint of a target range as the point target of a quadratic loss function.

${ }_{26}$ As inflation-targeting central banks, like other central banks, also seem to smooth instruments, the loss function (3.1) may also includes a term $\nu\left(i_{t}-i_{t-1}\right)^{2}$ with $\nu>0$. 
[41], King [59], Taylor [101] and Svensson [90] in Federal Reserve Bank of Kansas City [40] all discuss inflation targeting with reference to a loss function of the form (3.1) with $\lambda>0$. As shown in Svensson [91] and Ball [3], concern about output-gap stability translates into a more gradualist policy. Thus, if inflation is away from the inflation target, it is brought back to target more gradually. Equivalently, inflation-targeting central banks lengthen their horizon and aim at meeting the inflation target further in the future. As further discussed in Svensson [93], concerns about output-gap stability, model uncertainty, and interest rate smoothing all have similar effects under inflation targeting, namely a more gradualist policy. Sveriges Riksbank [98] has explicitly expressed very similar views. ${ }^{27}$ The Minutes from Bank of England's Monetary Policy Committee [5] are also explicit about stabilizing the output gap. ${ }^{28}$ Several contributions and discussions by central bankers and academics in Lowe [67] express similar views. Ball [4] and Svensson [92] give examples of a gradualist approach of the Reserve Bank of New Zealand. Thus, it is seems noncontroversial that real-world inflation targeting is actually flexible inflation targeting, corresponding to $\lambda>0$ in (3.1).

The loss function above does not induce an average inflation bias, since the implicit output target is taken to be capacity output and therefore consistent with the natural-rate hypothesis (that monetary policy cannot systematically affect average unemployment/capacity utilization). Indeed, motivations for inflation targeting, by governments, parliaments and central banks, put much emphasis on the natural-rate hypothesis, and it can be argued that the hypothesis constitutes one of the foundations of inflation targeting. The high degree of transparency and accountability in inflation targeting may then ensure that any concern about the real economy is consistent with the natural-rate hypotheses and therefore reduces, or eliminates, any inflation bias, which arguably translates into an output level target in (3.1) which is given by capacity output.

This highlights a fundamental asymmetry between inflation and output in inflation targeting. There is both a level goal and a stability goal for inflation, and the level goal, that is the inflation target, is subject to choice. For output, there is only a stability goal and no level goal. Or, to put it differently, the level goal is not subject to choice; it is given by the capacity of the output level. Therefore, I believe it is appropriate to label minimizing (3.1) as "(flexible) inflation targeting" rather than "inflation-and-output-gap targeting," especially since the label is already used for the monetary policy regimes in New Zealand, Canada, U.K., Sweden and Australia. ${ }^{29}$ For convenience, I shall consequently use the term "inflation-forecast targeting" below, rather than the somewhat clumsy "inflation-forecast-and output-gap-forecast targeting."

\subsection{Inflation-forecast targeting}

The greatest problem with inflation targeting is arguably the central bank's imperfect control of inflation. Inflation control is imperfect due to lags in the transmission mechanism, uncertainty about the transmission mechanism, the current state of the economy and future shocks to the

\footnotetext{
${ }^{27}$ See box on p. 26 in Sveriges Riksbank [98].

${ }^{28}$ See Bank of England [5], para. 40: “... [I]n any given circumstances, a variety of different interest rate paths could in principle achieve the inflation target. What factors were relevant to the preferred profile of rates?... There was a broad consensus that the Committee should in principle be concerned about deviations of the level of output from capacity."

${ }^{29}$ However, admittedly the label "inflation targeting" seems inappropriate if $\lambda$ is very large, so it is understood that the label refers to (3.1) with a $\lambda$ of at most moderate size.
} 
economy, and the influence of other factors than monetary policy on inflation, in particular shocks that occur within the control lag. The imperfect control makes the implementation of inflation targeting hard. It also makes the monitoring of inflation targeting difficult, since it is hard to extract how much of observed inflation is due to monetary policy some two years ago rather than to shocks and other factors having occurred during the control lag. With monitoring made difficult, the accountability and transparency of inflation targeting is reduced, and many potential benefits of inflation targeting may not materialize.

In Svensson [91], it is argued that there is a solution to this formidable problem, namely to use a conditional inflation forecast as an intermediate target variable. ${ }^{30}$ As emphasized in section 2, using conditional forecasts as intermediate target variables is arguably the most efficient way of implementing monetary policy, since it can be interpreted as implementing first-order conditions for a minimum of the loss function, using all the relevant information.

With this view, inflation-forecast targeting can be seen as an optimal intermediate-targeting rule. In short, it can be interpreted as a way for the central bank of implementing first-order conditions for an optimum, and as a way for outsiders of monitoring and verifying that those first-order conditions are fulfilled. ${ }^{31}$

In terms of the analysis in section 2, according to (3.1) the target variables (inflation and the output gap) are given by the vector $Y_{t}=\left(\pi_{t}, y_{t}\right)^{\prime}$. The corresponding "canonical" intermediate target variables in period $t$ are given by $Z_{t+\tau, t} \equiv Y_{t+\tau \mid t}=\left(\pi_{t+\tau \mid t}, y_{t+\tau \mid t}\right)^{\prime}$. The task for the central bank is then to find a future path for the instrument, $i^{t}=\left(i_{t}, i_{t+1 \mid t}, \ldots\right) \in \mathcal{I}_{t}$ such that the corresponding paths for inflation and the output gap, $Y^{t}=\left(Y_{t}, Y_{t+1 \mid t}, \ldots\right) \in \mathcal{Y}_{t}$, are optimal, that is, to minimize the intermediate loss function (2.4) and thereby fulfill the first-order conditions (2.20).

How can this be achieved in practice? The staff at the central bank can generate a collection of feasible inflation and output gap paths for different instrument paths for the MPC (or the Board). In this way, the staff shows the set feasible conditional forecasts, $\mathcal{Y}_{t}$, to the MPC. The MPC then selects the conditional forecasts of inflation and the output gap that "look best," that is, that return inflation to the inflation target and the output gap to zero at an appropriate rate. If this selection is done in a systematic and rational way, it is approximately equivalent to minimizing a loss function like (3.1) over the set of feasible conditional forecasts, $\mathcal{Y}_{t}$. The corresponding instrument path is then the basis for the current instrument setting.

This operating procedure implies that all relevant information is used in conducting monetary policy. It also implies that there is no explicit instrument rule, that is, the current instrument setting is not a prescribed explicit function of current information. Instead, the procedure results in an endogenous implicit reaction function, where the instrument ends up as an implicit function of the relevant information. The reaction function will, in general, not be a Taylor-type reaction function (where a Taylor-type reaction function denotes a reaction function rule which is a linear

\footnotetext{
${ }^{30}$ As far as I know, the idea that the inflation forecast becomes an intermediate target under inflation targeting was first expressed in print by King [58], p. 118: "The use of an inflation target does not mean that there is no intermediate target. Rather, the intermediate target is the expected level of inflation at some future date chosen to allow for the lag between changes in interest rates and the resulting changes in inflation. In practice, we use a forecasting horizon of two years."

31 As is emphasized in Svensson [91] and [93], it is important that the forecast is the central bank's internal structural forecast, and not an external forecast or market expectation. If the central bank instead lets the instrument react to market expectations in a mechanical way, there may be instability, nonuniqueness or nonexistence of equilibria, as has been shown by Woodford [111] and further discussed in Bernanke and Woodford [11]
} 
function of current inflation and output only), except in the special case when current inflation and output are sufficient statistics for the state of the economy. Typically, it will be dependent on much more information; indeed, on anything affecting the central bank's conditional inflation and output forecasts. Especially, the more open the economy, the more the reaction function will depend on foreign variables, for instance foreign inflation, output and interest rates, since these will then have effects on the conditional inflation and output forecasts.

As an alternative to selecting the conditional inflation and output forecast that "look best", the staff and the MPC can choose to follow a more specific targeting-rule in the form of an equation that the relevant forecasts must fulfill. In the example in appendix $\mathrm{C}$, one such targeting rule is the first-order condition (C.6),

$$
\pi_{t+2 \mid t}-\hat{\pi}=-\frac{\alpha_{y} c(\lambda)}{1-c(\lambda)} y_{t+1 \mid t}
$$

"select the instrument such that deviation between the two-year conditional inflation forecast is $\frac{\alpha_{y} c(\lambda)}{1-c(\lambda)}$ times the negative of the one-year output-gap forecast."

This example involves both inflation and output forecasts. What about targeting rules that involve only inflation forecasts? Within the same example, one such trivial rule arises under strict inflation targeting, when $\lambda=c(\lambda)=0$,

$$
\pi_{t+2 \mid t}=\hat{\pi}
$$

"set the instrument such that the conditional inflation forecast at the two-year horizon (or, more generally, at the shortest horizon at which inflation can be affected) equals the inflation target." Under more realistic flexible inflation targeting, the targeting rule can be written as (C.9),

$$
\pi_{t+2 \mid t}-\hat{\pi}=c(\lambda)\left(\pi_{t+1 \mid t}-\hat{\pi}\right),
$$

"set the instrument such that the two-year conditional inflation forecast's deviation from the inflation target is the fraction $c(\lambda)$ of the one-year conditional inflation forecast's deviation." ${ }^{32}$

Another targeting rule for flexible inflation targeting is "set the instrument such that the conditional inflation forecast hits the inflation target in quarter $T$," where $T$ is selected to be larger than the minimum control lag (the shortest horizon at which inflation can be affected). Note that this targeting rule, "aiming at the inflation target $T$ quarters ahead," does not mean that, in the absence of future shocks, inflation is actually likely to hit the inflation target $T$ quarters ahead. Instead, it implies a gradual approach, much like (3.3), since after one quarter, the central bank will still be aiming $T$ rather than $T-1$ quarters ahead. In order to see this, assume for simplicity that the inflation forecast is predetermined up to 4 quarters ahead but can be controlled from 5 quarters ahead and that the inflation forecast is a straight line from quarter 4 to quarter $T>5$. This means that the deviation of the inflation forecast 5 quarters ahead from the inflation target is the fraction $\frac{T-5}{T-4}$ of the deviation of inflation 4 quarters ahead, that is,

$$
\pi_{t+5 \mid t}-\hat{\pi}=\frac{T-5}{T-4}\left(\pi_{t+4 \mid t}-\hat{\pi}\right)
$$

\footnotetext{
${ }^{32}$ Note that if (3.2) and (3.3) are used to eliminate $\hat{\pi}_{t+2 \mid t}-\hat{\pi}$, the following targeting rule for the output-gap forecast arises: $y_{t+1 \mid t}=-\frac{1-c(\lambda)}{\alpha_{y}}\left(\pi_{t+1 \mid t}-\hat{\pi}\right)$.
} 
which with appropriate choice of $T$ is similar to (3.3). ${ }^{33}$

Another targeting rule, that can arguably be inferred from the minutes of Bank of England's MPC (see footnote 28), is to "select the instrument path such that the deviations of output from capacity output are minimized, subject to the inflation forecast hitting the inflation target eight quarters ahead."

These examples of specific inflation-forecast targeting rules (with or without involving explicit conditional output-gap forecasts) can be seen as "rules of thumb" that may simplify the selection of the optimal path of forecasts for the MPC. They can also serve a role in simplifying communication with the private sector, as discussed in the next section. However, they are of course only optimal for the loss function (3.1) under special circumstances (for instance, if the model is similar to the model in appendix C). The performance and robustness of these and other specific targeting rules for other models remain an unexplored issue.

Inflation-targeting central banks will no doubt continue to develop and experiment with different specific targeting rules, both in order to simplify the selection of the optimal paths of the target variables and in order to simplify communication with the private sector; in this way developing and improving the practice of inflation targeting.

von Hagen [107] emphasizes that an intermediate target provides a focal point in the monetary policy discussion and defines the admissible arguments in the discussion preceding monetary policy decisions. Thus, using a conditional forecast as an intermediate target makes the forecast the focal point in the discussion. One aspect of this is that the advantage of relying on conditional inflation forecasts is that this induces some discipline when applying judgements and extra-model information. In order to allow judgements and extra-model information to affect the current instrument setting, a coherent and convincing argument for why such judgements or information affect the conditional inflation forecast at the appropriate horizon must be presented. Only if the conditional forecast can be shown to be thus affected, can any corresponding current instrument adjustment be motivated.

Generally, practical monetary policy, especially forecasting, cannot rely on models alone (at least not yet). It seems that judgemental adjustments and extra-model information will always be necessary and constitute a natural part of practical monetary policy. It is far from obvious how to make judgemental adjustments of models and their results, and how to include extramodel information, in reasonably consistent ways. ${ }^{34}$ Still, in terms of the forward-looking model used in section 2, judgemental adjustments can be incorporated by adjusting the coefficients of matrices $A$ and $B$ in (2.1), for instance by shifting intercepts of model equations (so-called "add-factors" in the jargon of modelers and forecasters). As a result, the matrices become timedependent. The algorithms used to calculate conditional forecasts and discretion equilibria, cf. appendix A, are easily adapted to time-varying matrices.

The above examples of targeting rules also generally show how the central bank should respond to new information, for instance to various shocks: Decide whether the shock affects the conditional forecasts at the relevant horizon. If so, adjust the instrument to counter (wholly or partially, depending upon the desire to smooth interest rates) the effect of the shocks on the forecast. ${ }^{35}$

\footnotetext{
${ }^{33}$ Note that under the assumptions made, $\pi_{t+\tau \mid t}=\hat{\pi}+\frac{T-\tau}{T-4}\left(\pi_{t+4 \mid t}-\hat{\pi}\right), \tau=4,5, \ldots, T$.

${ }^{34}$ See Reifschneider, Stockton and Wilcox [80] for further discussion of judgemental adjustements.

${ }^{35}$ Freedman [42] provides an insightful and more detailed discussion of the implementation of inflation targeting.
} 


\subsection{Transparency}

Real-world inflation-targeting regimes are characterized by a high degree of transparency and accountability. Inflation-targeting central banks issue regular reports explaining and motivating their policy to the general public. The Reserve Bank of New Zealand, the Bank of England and Sveriges Riksbank publish graphs of a conditional inflation forecast. Bank of England publishes the minutes of the meeting of its Monetary Policy Committee within six weeks of each meeting. In New Zealand, the Reserve Bank Governor's performance will be evaluated by the Reserve Bank's Board of Directors, and his job potentially at risk, if inflation moves outside the 03 percent target range. In the U.K., the Chancellor of Exchequer has announced the "Open Letter System": If inflation deviates more than 1 percentage point from the 2.5 percent inflation target, the Governor of the Bank of England shall explain in an open letter why the divergence has occurred and what steps the Bank is taking to deal with it.

Which is the role of transparency in monetary policy in general, and in inflation targeting in particular? Building on previous work by Cukierman and Meltzer [29], Faust and Svensson [39] have recently examined the general role of transparency in monetary policy. They examine a model with a central bank that is tempted to deviate from an announced inflation target due to fluctuations in an idiosyncratic employment target. The employment target is private information to the central bank and unobservable to the private sector. For instance, it represents changes in the composition of the MPC/Board, or the response of the bank to external pressure from various special interests. The private sector observes the macroeconomic outcome and imperfectly infers the central bank's employment target, which gives rise to the bank's reputation in the private sector and corresponding private-sector inflation expectations.

Increased transparency allows the private sector to infer the bank's employment target with greater precision, which makes the bank's reputation and corresponding private-sector inflation expectations more sensitive to the bank's actions. This, in turn, increases the cost for the bank of deviating from the announced inflation target and pursuing its idiosyncratic employment target. Consequently, increased transparency induces the bank to follow the announced policy more closely. It simply provides an implicit commitment mechanism.

Whereas society almost always prefers more transparency to less, the central bank often prefers less transparency, since it allows the bank to pursue its idiosyncratic goals with less cost to its reputation. An obvious conclusion from this finding is that society, rather than the bank, should decide on the degree of transparency.

I believe these results from Faust and Svensson [39] to be consistent with the general view that transparency facilitates public understanding of monetary policy and increases the incentives for the central bank to pursue the announced goals for monetary policy and thereby to improve credibility for those goals. Consider the three-part scheme of efficient delegation of monetary policy: (1) society announces goals for monetary policy, (2) the central bank receives instrument independence to pursue the goals, (3) the central bank is accountable to society for fulfilling the goals for monetary policy. Transparency is then crucial for the accountability of the central bank, that is, for society's monitoring of monetary policy.

Under inflation targeting, reporting the central bank's conditional inflation and output forecasts (including the information, assumptions, models and judgements used in its construction) allows outsiders to monitor and scrutinize the conditional forecasts, both with regard to their 
being consistent with the inflation target, and their having been constructed in a professional and unbiased way (for instance, by comparison with reputable outsiders' competing forecasts). In particular, the evaluation of monetary policy does not have to be postponed some two years for inflation to be observed, instead evaluation can be made almost in real time. The more explicit the bank is about the applied targeting rule, the easier it is for the outsiders to monitor the extent to which it is fulfilled, and the stronger the incentives for the bank to actually fulfill it.

The inflation-targeting central banks explain and motivate their policy in regular Inflation Reports or Monetary Policy Statements. Three of the inflation-targeting banks, Reserve Bank of New Zealand, Bank of England, and Sveriges Riksbank, publish graphs of conditional inflation forecasts, such that outside observers can check whether the targeting rule, that is, the firstorder conditions, are fulfilled. Reserve Bank of New Zealand comes closest to plotting optimal conditional forecasts for the crucial variables. It plots paths for inflation, the output gap, a three-month interest rate and the exchange rate (including nominal and real MCI paths) for the next three years.

Bank of England (since its first Inflation Report in February 1993) and Sveriges Riksbank (since its Inflation Report of December 1997) plot a conditional inflation forecast for a constant unchanged interest rate, $i_{t+\tau \mid t}=i_{t}(\tau \geq 0)$. Since November 1997, Bank of England also plots a corresponding forecast for output. The role of an unchanged-interest-rate forecast is, of course, to illustrate the likely future outcome if interest rates are held constant, and in this way motivate any required interest rate adjustment. If the corresponding forecasts are not consistent with the inflation target, this indicates both that an adjustment of the interest rate is warranted and in which direction this adjustment should be made. If the forecasts are consistent with the inflation target, this indicates that no immediate change in the interest rate is required.

Furthermore, Bank of England stands out by publishing minutes of the MPC meetings, including voting records. These minutes provide an exceptional opportunity for outsiders to monitor the quality and the appropriateness of the information and the arguments presented during the monetary policy discussion. The published voting records assign individual responsibility to MPC members. I believe it fair to say that never before in monetary history has an incentive system been set up with such strong incentives for optimal monetary policy decisions. ${ }^{36}$

I believe that the characteristics of inflation targeting imply that it is a much stronger commitment to a systematic and rational optimizing monetary policy than other monetary policy regimes. The explicit target implies a relatively explicit loss function. The operating procedure is a rational way of minimizing that loss function. The operating procedure can be interpreted as a way of ensuring that first-order conditions for minimizing the loss function are approximately fulfilled. The high degree of transparency and accountability allows outsiders to monitor whether monetary policy is indeed optimizing and thereby reinforces the incentives to such policy. The Inflation Reports can be interpreted as reports on whether first-order conditions are approximately fulfilled. ${ }^{37}$

\footnotetext{
${ }^{36}$ A problem with publishing MPC minutes is that the discussion might be inhibited and that crucial discussions might be moved outside the MPC meetings. Bank of England's minutes do not state what was said by whom and only present summaries of the arguments, which should mitigate the first problem. Members with sufficient personal integrity not to consent to moving crucial discussions elsewhere should mitigate the second.

37 Sometimes I have met the objection that, when modeled as minimizing a loss function, inflation targeting is no different from any other kind of monetary policy. So what is new? I believe that the false inference in such objections is that any other monetary policy is always adequately modeled as optimizing. Indeed, I would like to
} 


\subsection{Model uncertainty and model robustness}

So far, the discussion has assumed that the model is known, and that there is only additive uncertainty with shocks with known stochastic properties. With additive uncertainty in a linear model with a quadratic loss function, certainty equivalence holds.

The consequences of parameter uncertainty in the form of exogenous random parameters were analyzed early in Brainard [17]. As is by now well-known, parameter uncertainty implies multiplicative rather than additive uncertainty, and certainty-equivalence breaks down. In many cases, the optimal policy is then characterized by increased caution and less aggressive responses. In the context of inflation targeting, this implies a more gradual approach of inflation towards the inflation target and has similar effects as more weight on stabilizing output-gap variability (a higher $\lambda$ ) (see Svensson [93]). However, different patterns of covariance between random parameters can overturn this result and lead to more aggressive responses.

In situations when model parameters are stable or serially correlated but unknown to the central bank, the central bank's learning, for instance in the form of accumulating more data, allows the central bank to estimate the unknown parameters with greater precision (see for instance Sargent [85]). As demonstrated by Wieland [109] and [110], the central bank may then have an incentive to experiment and in the short run pursue a policy that generates more informative data in order to achieve a better policy in the long run. Then the variance and covariance of parameters are endogenous and not exogenous as in the Brainard case. The optimal response seems to be a compromise between the certainty-equivalent policy and the cautious Brainard policy.

Naturally, the optimal reaction function generally depends on the precise model structure. With uncertainty about the model structure, one possibility is to look for robust policy rules that are not necessarily optimal in any given model but perform reasonably well in a set of potential models. McCallum has, in several papers, developed his monetary-base instrument rule (2.14) as a potentially robust rule (see McCallum [70] for a summary of this work). Recently, Levin, Wieland and Williams [66] examined robust instrument rules in a set of different models used at the Federal Reserve Board. Their results indicate that optimal instrument rules are not very robust, whereas some simple instrument rules may be relatively robust. Furthermore, for the models examined, the optimal unrestricted instrument rules provide only little gain over the optimal simple instrument rules.

Work on so-called robust control under model uncertainty (Hansen and Sargent [52]) uses a

argue that other kinds of monetary policy have often not been optimizing. Instead, behind a thick veil of central bank secrecy and mystique, it has often been unsystematic and ad hoc, without stable explicit or implicit goals, or with contradictory or arbitrarily shifting goals.

For instance, the Humphrey/Hawkins bill arguably lists contradictory goals for the Federal Reserve System, and any move towards a more consistent bill about the goals of monetary policy seems stalled. FOMC members are sometimes reported to have different objectives and different perceived models of the economy. Kohn [64] notes that FOMC members need not necessarily agree on what monetary policy strategy to pursue. Some FOMC members have expressed sympathy for the so-called opportunistic approach to disinflation. Speeches by the current Fed Chairman are often ambiguous. The result is a considerable uncertainty about the goals of the FOMC, also among insiders.

For a few years, it seemed as if the hypothesis of the FOMC having a 3 percent per year inflation target could not be rejected. Now, when inflation has fallen below 2 percent per year, there is uncertainty (also expressed by insiders) about whether the FOMC will take 2 percent inflation as an implicit target, or whether the FOMC will let inflation drift up to 3 percent again. "One doesn't know whether the FOMC wants inflation to move up or down," as Alan Blinder expressed it during the conference.

Faust [38] documents and formalizes a historical and political-economy argument that the Fed's structure nevertheless was an efficient response to public conflict over inflation's redistribution effects. 
minimax criterion for choosing the robust instrument rule. Then the reaction function is chosen so as to minimize the loss function for the least favorable model in the set of potential models. As Sargent [86] and Stock [88] show, this criteria may imply more aggressive responses than under model certainty, counter to standard result of Brainard [17].

As concerns the difference between targeting rules and instrument rules, the optimal instrument rules generally depend on all model parameters, whereas even rather specific targeting rules are arguably more model-robust than instrument rules in that they may depend on only parts of the model. For instance, the different targeting rules that arise in the model of appendix $\mathrm{C}$ depend only on the parameters of the aggregate supply equation and the loss function, and they are, in contrast to the corresponding instrument rule, independent of the parameters of the aggregate demand equation. In general, a targeting rule like "aim for the inflation target 8quarters ahead" could be relatively model-robust, in the sense that it provides good performance in several different potential models. However, the construction of the relevant conditional inflation forecast of course depends also on the aggregate demand equation and generally on the whole model of the economy.

It goes without saying that more research on model uncertainty and model-robustness should be both of considerable theoretical and practical interest.

\section{Other monetary policy strategies}

This section discusses two other monetary policy strategies. In the discussion in Europe about the monetary policy strategy of the ESCB, the main competitor to inflation targeting is monetary targeting or, more precisely, money-growth targeting. In the United States, there are many proponents of nominal-GDP targeting. Hence, I will briefly discuss money-growth targeting and nominal-GDP targeting, as well as provide some comparisons with inflation targeting. Another alternative, namely the absence of an explicit monetary strategy, which is one way of characterizing the monetary policy of the Federal Reserve System, will not be discussed here. ${ }^{38}$

Both money-growth targeting and nominal-GDP targeting are interpreted as intermediatetargeting rules, that is, the assignment or adoption of an intermediate loss function with money growth or nominal GDP as a target variable. Since the purpose of an intermediate-targeting strategy is to fulfill some final loss function, the performance of the intermediate-targeting rule must be evaluated according to that final loss function rather than to the intermediate loss function. The final loss function is taken to be (3.1) and hence corresponds to (flexible) inflation targeting.

\subsection{Money-growth targeting}

The main point in this subsection is that money-growth targeting, seen as a strategy for achieving price stability by stabilizing inflation around a given inflation target, faces an unpleasant choice between being either inefficient and transparent or efficient and nontransparent.

Money-growth targeting would be the optimal way of fulfilling an inflation target, if money growth were the sole predictor of future inflation. More specifically, and with reference to the

\footnotetext{
${ }^{38}$ See, for instance, Blinder [16], Bernanke, Laubach, Mishkin and Posen [7] and Rudebusch and Walsh [84] for the few pros and the many cons incurred by the absence of an explicit monetary strategy.
} 
discussion in section 2.3.4, for money growth to be the ideal intermediate target, the monetary policy instrument should affect the future price level only via its effect on money, schematically represented as

$$
i_{t} \rightarrow m_{t+1} \rightarrow \pi_{t+2}
$$

That is simply not the case. The increasingly dominating conventional wisdom about the transmission mechanism of monetary policy, outlined in section 2.1 , heretically only assigns a minor role to monetary aggregates. Accordingly, money growth is generally not an ideal intermediate target. Money-growth targeting must be conditional to be efficient, in the sense that the money-growth target is frequently revised in a complex way, where the role of the money-growth target is simply to generate an instrument level corresponding to a complex reaction function. Alternatively, the money-growth target is left unconditional, but must then be frequently and intentionally missed. The complex reasons for target revisions, or for target misses, thus make money-growth targeting non-transparent. It is then simply "inflation targeting in disguise".

Let $\mu_{t} \equiv m_{t}-m_{t-1}$ denote money growth, where $m_{t}$ is the (log) quantity of a given monetary aggregate, say M3. Let $\hat{\mu}$ denote the target level for money growth, and interpret money-growth targeting as implying an intertemporal loss function (2.4) with the period loss function

$$
L_{t}=\frac{1}{2}\left(\mu_{t}-\hat{\mu}\right)^{2} .
$$

That is, the target variable and the target level are given by $Y_{t} \equiv \mu_{t}$ and $\hat{Y}_{t}=\hat{\mu}$. Thus, moneygrowth targeting can be interpreted as a targeting rule: "Use all available information to bring money growth $\mu_{t}$ as close to $\hat{\mu}$ as possible." 39

Under perfect control of money growth, the first-order condition for a minimum of (4.1) is trivial,

$$
\mu_{t}=\hat{\mu} \text {. }
$$

Under more realistic imperfect control of money growth, the first-order condition can be written

$$
\mu_{t+T \mid t}=\hat{\mu}
$$

where $T \geq 0$ is the (shortest) control lag for money growth. That is, the $T$-period-ahead conditional forecast of money growth, $\mu_{t+T \mid t}$, should equal the money growth target. As observed in Svensson [91], under imperfect control, money-growth targeting is indeed money-growthforecast targeting, and can be stated as the targeting rule: "Set the instrument so as to bring the conditional money-growth forecast at the appropriate horizon equal to the target."

In order to see the implications, assume, for example, a simple money demand equation with a one-period lag,

$$
m_{t+1}-p_{t+1}=\varphi_{y} y_{t}-\varphi_{i}\left(i_{t}-\bar{i}\right)-\zeta_{t+1},
$$

where $\varphi_{y}>0, \varphi_{i}>0, i_{t}$ is a short nominal interest rate, $\bar{i}$ is the steady state level of the nominal interest rate that, with $y_{t}=\zeta_{t}=0$, results in $m_{t}-p_{t}=0$, and $\zeta_{t}$ is an iid shock to demand (and velocity) with zero mean and variance $\sigma_{\zeta}^{2}{ }^{40}$ This money-demand equation should

\footnotetext{
${ }^{39}$ Note that we could consider "flexible" money-growth targeting corresponding to $L_{t}=\frac{1}{2}\left[\left(\mu_{t}-\hat{\mu}\right)^{2}+\lambda y_{t}^{2}\right]$.

${ }^{40}$ Note that velocity, $w_{t+1} \equiv p_{t+1}+y_{t+1}-m_{t+1}$, then fulfills

$$
w_{t+1}=y_{t+1}-\varphi_{y} y_{t}+\varphi_{i}\left(i_{t}-\bar{i}\right)+\zeta_{t+1} .
$$
}


be interpreted as referring to a broad money aggregate, say M3, which is an endogenous variable and not under perfect control by the central bank. Instead, the central bank uses its instrument, the short nominal rate $i_{t}$, to affect the demand for real balances, $m_{t}-p_{t}$. Real-balances are considered to be demand-determined and adjust to the output gap and the interest rate with a one-period lag. That is, the control lag, $T$, fulfills $T=1$.

With this money-demand equation, money growth is given by

$$
\mu_{t+1} \equiv m_{t+1}-m_{t}=\pi_{t+1}+\varphi_{y}\left(y_{t}-y_{t-1}\right)-\varphi_{i}\left(i_{t}-i_{t-1}\right)-\left(\zeta_{t+1}-\zeta_{t}\right)
$$

Hence, the one-period-ahead conditional money-growth forecast is

$$
\mu_{t+1 \mid t} \equiv \pi_{t+1 \mid t}+\varphi_{y}\left(y_{t}-y_{t-1}\right)-\varphi_{i}\left(i_{t}-i_{t-1}\right)+\zeta_{t}
$$

The first-order condition (4.2) for $T=1$, the targeting rule for money-growth targeting, then results in the reaction function

$$
i_{t}-i_{t-1}=\frac{1}{\varphi_{i}}\left(\pi_{t+1 \mid t}-\hat{\mu}\right)+\frac{\varphi_{y}}{\varphi_{i}}\left(y_{t}-y_{t-1}\right)+\frac{1}{\varphi_{i}} \zeta_{t}
$$

(it is assumed that $\pi_{t+1 \mid t}$ is predetermined, as in the models in appendices $\mathrm{C}$ and $\mathrm{D}$ ).

Thus, as discussed in Taylor [102], money-growth targeting implies a particular reaction function for the interest rate. We note that very little information about the economy is used in the construction of this reaction function. The instrument only depends on the parameters of the money-demand function, the money-growth target and the information predicting money demand. No other information about the model is used, for instance the equations for aggregate supply and demand, nor is any other information about the state of the economy that predicts future inflation. ${ }^{41}$

We immediately realize that, relative to a loss function like (3.1), the reaction function (4.6) is generally inefficient, notwithstanding if $\lambda=0$ or $\lambda>0$, . If the money-growth target is set equal to the inflation target,

$$
\hat{\mu}=\hat{\pi},
$$

we realize that the average inflation will equal the inflation target, $\mathrm{E}\left[\pi_{t}\right]=\hat{\pi}$, but (3.1) will not be minimized. The variability of inflation or of the output gap, or of both, will be unnecessarily large.

We also note that money-growth targeting in the above sense does not imply

$$
i_{t}-i_{t-1}=\gamma\left(\mu_{t}-\hat{\mu}\right)
$$

Thus, it does not necessarily follow from the empirical observation that money or money growth does not enter Bundesbank's reaction function, that Bundesbank is not targeting money growth (in the sense of minimizing (4.1)), counter to the apparent conclusion in Clarida, Gali and Gertler [24]. Additional (easily available) evidence is needed for this conclusion, for instance, that Bundesbank has systematically and intentionally missed its money growth target (in the sense that it has accepted conditional money-growth forecasts at the appropriate horizon, in order to deviate from the money-growth target). The difference between (4.6) and (4.8) is

\footnotetext{
${ }^{41}$ For instance, compared with the optimal reaction function (C.11) in appendix C, there is no reaction to $z_{t}$.
} 
another example of the result that it is better to respond to the determinants of target variables than to the target variables themselves, as is further discussed in Svensson [94].

As discussed in Svensson [91], money-growth targeting can be efficient relative to (3.1), if it is "conditional", such that the money-growth target level is conditional on period- $t$ information. ${ }^{42}$ Let $\hat{\mu}_{t+1 \mid t}$ denote this conditional money-growth target, so that the first-order condition and targeting rule is

$$
\mu_{t+1 \mid t}=\hat{\mu}_{t+1 \mid t} .
$$

The conditional money-growth target $\hat{\mu}_{t+1 \mid t}$ can be set such that the resulting reaction function (4.6) with $\hat{\mu}$ replaced by $\hat{\mu}_{t+1 \mid t}$ coincides with the optimal reaction function for minimizing (3.1), namely (2.13). Then, $\hat{\mu}_{t+1 \mid t}$ is simply given by the right side of (4.5), where (2.13) is substituted for $i_{t}$. For instance, in the model laid out in appendix $\mathrm{C}$, with the optimal reaction function (C.11), $\hat{\mu}_{t+1 \mid t}$ should fulfill

$$
\begin{aligned}
\hat{\mu}_{t+1 \mid t}= & \pi_{t+1 \mid t}+\varphi_{y}\left(y_{t}-y_{t-1}\right) \\
& -\varphi_{i}\left[\bar{r}+\hat{\pi}+\left(1+\frac{1-c(\lambda)}{\alpha_{y} \beta_{r}}\right)\left(\pi_{t+1 \mid t}-\hat{\pi}\right)+\frac{\tilde{\beta}_{y}}{\beta_{r}} y_{t}+\frac{\beta_{z}}{\beta_{r}} z_{t}-i_{t-1}\right]+\zeta_{t} \\
= & \hat{\pi}+\left[1-\varphi_{i}\left(1+\frac{1-c(\lambda)}{\alpha_{y} \beta_{r}}\right)\right]\left(\pi_{t+1 \mid t}-\hat{\pi}\right)+\left(\varphi_{y}-\varphi_{i} \frac{\tilde{\beta}_{y}}{\beta_{r}}\right) y_{t}-\varphi_{y} y_{t-1} \\
& -\varphi_{i} \frac{\beta_{z}}{\beta_{r}} z_{t}+\varphi_{i}\left[i_{t-1}-(\bar{r}+\hat{\pi})\right]+\zeta_{t} .
\end{aligned}
$$

However, this complex conditional money-growth target is hardly transparent. In addition, it requires very precise information about the money demand function.

Therefore, money-growth targeting seems to face the unpleasant choice between being either unconditional, inefficient and transparent or conditional, efficient, and non-transparent. The difficulty with money-growth targeting is apparently that money growth is not the sole predictor of inflation. In the models in appendices $\mathrm{C}$ and $\mathrm{D}$, in particular, money growth has no additional predictive power beyond that of the other predetermined variables. For the simple model in $\mathrm{C}$, causality is schematically:

$$
\begin{aligned}
i_{t} & \rightarrow i_{t}-\pi_{t+1 \mid t} \rightarrow y_{t+1} \rightarrow \pi_{t+2} \\
& m_{t+1}
\end{aligned}
$$

The only role of the money-growth target is to generate the appropriate reaction function for the instrument. ${ }^{43}$

It is sometimes argued that monetary targeting should have the advantage over inflation targeting that it avoids reactions to one-time price level disturbances, and instead focuses on the trend rate of inflation. As far as I can see, no inherent feature in inflation targeting necessarily

\footnotetext{
${ }^{42}$ This is consistent with the discussion in von Hagen [107] about the observational equivalence of closed-loop monetary strategies.

43 The so-called $P^{*}$-model (see, for instance, Hallman, Porter and Small [51]) is often used in discussions of monetary targeting (for instance, von Hagen [106], Neumann [76] and Tödter and Ziebarth [105]). This may create the impression that the $P^{*}$ model gives some rationale for monetary targeting. As is examined in Svensson [95], the $P^{*}$-model implies a conventional Phillips curve with an interest term added, which, by itself, does not provide any specific rationale for monetary targeting.
} 
implies reactions to such one-time disturbances. The forward-looking nature of inflation targeting, for instance a two-year horizon, means that short term price-changes are ignored unless they affect inflation two years ahead. Furthermore, nothing prevents the index of inflation to focus on trend inflation. This can easily be done, and has already been done by some inflation-targeting central banks, by excluding some transitory components like mortgage costs, taxes and subsidies from the index, or by having an explicit index of trend inflation, "underlying" inflation.

How does the above discussion relate to Bundesbank monetary targeting? First, one must distinguish between stylized Bundesbank monetary targeting and the actual practice. In the above framework, stylized Bundesbank money-growth targeting corresponds to unconditional money-growth targeting, setting the money-growth target equal to the inflation target, (4.7). Each year, Bundesbank sets its money-growth target equal to the sum of an inflation target, $\hat{\pi}$ (called a price norm, "normative" inflation, or a "medium-term price assumption," previously 2 percent per year, currently 1.5-2 percent per year), a forecast of the growth of potential output, and an estimated trend in velocity. In the above framework, the growth of potential output is zero, and by (4.3) the trend in velocity is also zero.

In practice, Bundesbank has frequently deviated from its money-growth targets (see the graph on p. 69 in Bundesbank [34]). It appears that when a conflict has arisen between the money-growth target and the inflation target, Bundesbank has given priority to the latter. Indeed, Bundesbank's credibility and reputation definitely appears to be due to its inflation performance, and not to its money-growth performance. ${ }^{44}$ Thus, Bundesbank's monetary policy indeed appears to have been inflation targeting in disguise. ${ }^{45}$

\subsection{Nominal GDP-growth targeting}

Nominal-GDP targeting comes in two variants, level targeting and growth targeting. The discussion here refers to nominal GDP-growth targeting, but it is easily adapted to nominal GDP-level targeting.

The main points in this subsection are that nominal GDP-growth targeting does not seem to have any advantages relative to inflation targeting. There is no apparent rationale for the implicit constant unitary marginal rate of substitution between inflation and output growth. One possibility is that nominal GDP targeting is a left-over from a previous, somewhat simplistic, view of the transmission mechanism for monetary policy. According to this view, monetary policy only determines nominal GDP, but cannot affect the distribution of nominal GDP between inflation and output growth.

Thus, consider nominal GDP-growth targeting. Assume that the natural output level is constant, so that output varies with the output gap. Let

$$
g_{t} \equiv \pi_{t}+y_{t}-y_{t-1}
$$

denote nominal GDP growth. Interpret nominal GDP-growth targeting as involving a period loss function

$$
L_{t}=\frac{1}{2}\left(g_{t+\tau}-\hat{g}\right)^{2}
$$

\footnotetext{
${ }^{44}$ Cf. von Hagen [106], p. 108: "As Issing [56] emphasizes, the Bank's credibility depends on its performance with regard to price stability, i.e. the inflation target."

${ }_{45}$ See Bernanke and Mihov [9] and Clarida and Gertler [26].
} 
where $\hat{g}$ is the nominal GDP-growth target. That is, the target variable and the target level are given by $Y_{t} \equiv g_{t}$ and $\hat{Y} \equiv \hat{g}$. (The "reaction-function" interpretation of nominal GDP-growth targeting, where the reaction function is restricted to be (similar to)

$$
i_{t}=\bar{i}+\gamma\left(g_{t}-\hat{g}\right)
$$

is examined below.)

First, relate the period loss function (4.10) to the loss function under inflation targeting (3.1). We can write (4.10) as

$$
L_{t}=\frac{1}{2}\left(\pi_{t}+y_{t}-y_{t-1}-\hat{g}\right)^{2}=\frac{1}{2}\left[\left(\pi_{t}-\hat{g}\right)^{2}+y_{t}^{2}\right]+\frac{1}{2} y_{t-1}^{2}-y_{t} y_{t-1}+\left(\pi_{t}-\hat{g}\right) \Delta y_{t} .
$$

If $\hat{g}=\hat{\pi}$, the term within brackets on the right side corresponds to the inflation-targeting loss-function (3.1), with $\lambda=1$. Furthermore, the two loss functions differ by the other terms on the right side of (4.11). Intuitively, the loss function for inflation targeting has a variable "decreasing" intra-temporal marginal rate of substitution between inflation and the output gap, $\left.\frac{d y_{t}}{d \pi_{t}}\right|_{\bar{L}_{t}}=-\frac{\pi_{t}}{\lambda y_{t}}$, whereas the loss function for nominal GDP-targeting has a unitary intratemporal marginal rate of substitution between inflation and output growth $\left.\frac{d\left(y_{t}-y_{t-1}\right)}{d \pi_{t}}\right|_{\bar{L}_{t}}=-1$.

The first-order condition for a minimum of (2.4) with (2.3) is

$$
g_{t+T \mid t}=\hat{g}
$$

where $T \geq 1$ is the control lag (the shortest horizon at which the central bank can affect nominal GDP).

Thus, under realistic imperfect control, nominal GDP-growth targeting is nominal GDPgrowth forecast targeting, and can be formulated as the targeting rule: "Set the instrument so as to bring the conditional nominal-GDP forecast at the appropriate horizon in line with the target." 46

Generally, nominal GDP-growth targeting results in an optimal reaction function of the form,

$$
i_{t}=f X_{t},
$$

that results from inverting (4.12). Generally, the optimal reaction function will not imply responding only to the deviation of nominal GDP-growth from the target, for instance,

$$
i_{t}=\bar{i}+\gamma\left(g_{t}-\hat{g}\right) \text {. }
$$

As further discussed in Svensson [94], the optimal reaction function does not imply a response to this deviation at all. Instead, it involves responding to the different determinants of nominal GDP-growth.

The current framework does not seem to provide any rationale for the "reaction-function" interpretation of nominal GDP, (4.13). This reaction function is inefficient for stabilizing inflation and output according to (3.1), as well as (perhaps somewhat surprising) being inefficient for stabilizing nominal GDP growth around the target according to (4.10). ${ }^{47}$

\footnotetext{
${ }^{46}$ As shown in Ball [3] and further discussed in Svensson [93], (4.12) leads to instability with a backward-looking model and lag structure as in Svensson [91]. As shown in [93], the lag structure with a shorter control lag for aggregate demand than for inflation seems necessary for this instability result. McCallum [71] and Dennis [35] emphasize the sensitivity of Ball's instability result.

${ }^{47}$ See McCallum and Nelson [73] for arguments in favor of reaction-function nominal income targeting.
} 
As noted in Svensson [93], a sometimes-mentioned rationale for nominal GDP targeting is that monetary policy can only determine nominal GDP growth, but not the decomposition of nominal GDP growth into inflation and real GDP growth. It is sometimes claimed that little is understood about the determinants of that decomposition. Given such lack of understanding, it is considered safer for the central bank to achieve a certain nominal GDP growth rate, rather than to attempt to control inflation and/or output separately. Interestingly, the increasingly dominant conventional wisdom about the transmission mechanism outlined in section 2.1 is very different. There, the transmission mechanism of monetary policy goes via aggregate demand to inflation, with a longer control lag for inflation. Hence, in this model, the knowledge about the separate effects of the instrument on aggregate demand and inflation is substantial, in particular the different lags of those effects, and the nominal aggregate demand does not play any role in the transmission of monetary policy by itself.

\section{Monetary policy in the ESCB}

The European System of Central Banks (ESCB), consisting of the European Central Bank in Frankfurt (ECB) and the national central banks in the EMU (NCBs), faces some formidable problems, technical as well as political, for its monetary policy. The technical problems involve defining operational targets (specifying the loss function) that correspond to the goals stated in the Maastricht treaty, specifying operational procedures to find the feasible set of future paths for target variables (conditional forecasts of target variables, the set $\mathcal{Y}_{t}$ in section 2) and selecting the optimal path for the target variables and the corresponding instrument path. These technical problems are made much more difficult by the unavoidable uncertainty about the transmission mechanism for monetary policy in the new EMU and the resulting imperfect control of inflation. Also, and not least important, the ECB's Executive Board and Council and the staff of the ECB and the NCBs must have incentives to fulfill the goals of the institution.

The political problems include what legitimacy (for instance, the degree of public acceptance) the institution will receive, and what credibility and reputation the institution will have with regard to its commitment and ability to achieve its goals. These political problems are made more difficult by the possible (and even likely) conflict between national and EMU-wide interests. I will first discuss the technical problems and then proceed to the political ones.

\subsection{Technical problems}

According to Article 105(1) in the Maastricht Treaty, "The primary objective of the ESCB shall be to maintain price stability. Without prejudice to the objective of price stability, the ESCB shall support the general economic policies in the Community with a view to contributing to the achievement of the objectives of the Community as laid down in Article 2..." According to Article 2, the Community shall have as its task "to promote throughout the Community a harmonious and balanced development of economic activities, sustainable and non-inflationary growth respecting the environment, a high degree of convergence of economic performance, a high level of employment and of social protection, the raising of the standard of living and quality of life, and economic and social cohesion and solidarity among Member States."

EMI [36] and the newly appointed Executive Board of the ECB [37] have defined price 
stability as an inflation rate between 0 and 2 percent per year. This can be interpreted as a target range for an EMU-wide inflation of 0-2 percent per year, or as a point inflation target of 1 percent per year with a tolerance interval of \pm 1 percentage point. ${ }^{48}$

The second sentence in Article 105(1) can arguably be interpreted as including stabilization of real variables around their natural levels, that is, flexible rather than strict inflation targeting. This can be represented by an ESCB period loss function that includes stabilization of the output gap, as in (3.1) with $\lambda>0$. As emphasized above, this translates into a gradual adjustment of inflation towards the inflation target, and aims at the inflation target at a longer horizon. Furthermore, a loss function, as above, implies that the conditional inflation forecast will become an intermediate target at an appropriate horizon, say 2-2.5 years ahead. The task of the ECB is then to set its instrument, an EMU-wide short nominal interest rate, such that the corresponding conditional inflation forecast 2-2.5 years ahead hits the inflation target of 1 percent per year.

This is easier said than done. The main technical challenge for the ESCB will be to compute reliable and unbiased conditional forecasts for EMU-wide inflation, conditional upon the current state of the European economy, the ESCB's view of the transmission mechanism for EMU monetary policy, and given instrument paths, in order to find an instrument path that is consistent with meeting the inflation target. The lack of experience of an EMU-wide transmission mechanism for monetary policy and the corresponding unavoidable uncertainty about the transmission mechanism will then present a formidable difficulty. The introduction of the new common currency is obviously a major structural change in the economic structure of the EMU area. What are the consequences for the EMU transmission mechanism?

Interestingly, the view of the transmission mechanism outlined in section 2.1 de-emphasizes the role for money in the transmission mechanism; instead the focus is on the short real interest rate and aggregate demand and supply. ${ }^{49}$ A crucial issue then is the extent to which aggregate demand and supply relations change with the introduction of the new currency. One possibility is to think in terms of national transmission mechanisms, that is, with a common short nominal interest rate but different aggregate demand and aggregate supply relations in each country, giving rise to national inflation and output gaps (obviously with strong spill-over effects between countries, effects that should be stronger with a common currency). EMU inflation and output gaps will then be weighted averages of national ones. It is possible that the national aggregate demand and supply relations only change moderately with the new currency, and that previous relations continue to hold to a considerable extent. Constructing conditional national inflation forecasts may then be less difficult than one might at first think. In general, constructing national forecasts and then adding up to EMU-wide forecasts seems to be a more efficient use of national information, rather than trying to construct an EMU-wide forecast directly.

Thus, one possibility is that each national central bank is responsible for making conditional inflation forecasts for its national inflation, with the ECB being responsible for scrutinizing these forecasts as well as providing its own competing national forecasts. These forecasts can then be added up by ECB to provide EMU forecasts. ECB scrutiny in order to detect any bias in national forecasts may of course be rather important. ${ }^{50}$

\footnotetext{
${ }^{48}$ Alternatively, the $0-2$ statement might be interpreted in the way that any point inflation target $\hat{\pi}$ in the range $0-2$ percent would be consistent with price stability.

${ }_{49}$ Since EMU as a whole will be a less open economy than the individual countries, the open-economy aspects discussed in section 2.1 are arguably of less importance for EMU than for a small open economy.

50 It is an irony of history that the two European central banks with explicit inflation targeting and the
} 
In order to ensure sufficient independence from the national central banks, and in order to be able to effectively scrutinize the national forecasts, the ECB will also need to develope its own forecasting capacity, either by having a set of models for each country in the EMU, or by having an aggregate model for the EMU, or perhaps both. One possible advantage with an aggregate model is that some spillover effects between countries may cancel, and that errors in national forecasts may cancel in the aggregate forecast. Competition between the ECB and the national central banks may improve the total quality of the forecasts.

The ECB's Executive Board and Council, as well as the staff of the ECB and the NCBs, must also have the right incentives to fulfill the monetary goals. Such incentives are provided by peer pressure, and by a high degree of accountability to the European Parliament and to the general public. Transparency, with regular reports modeled on those of the Reserve Bank of New Zealand, Bank of England and Sveriges Riksbank, clear and explicit motivations for policy decision, and perhaps published minutes and voting records of the Council, are likely to be necessary. (A good name for the regular report may be Price Stability Report.) Accountability and transparency may also be crucial for dealing with the potential political problems of the ESCB.

\subsection{Political problems}

By all likelihood, a sustained successful monetary policy by the ESCB requires acceptance and legitimacy of the institution and its goals by politicians and the general public in the EMU. Monetary policy is also much more likely to be successful if it has credibility, that is, if market participants, politicians and the general public expect the ESCB to achieve its primary goal, that is, price stability. A high degree of transparency is likely to be essential for this purpose.

By having an explicit inflation target, and by issuing a regular Price Stability Report with an explicit conditional inflation forecast (as well as the analysis and assumptions behind it), the ESCB can increase its accountability, simplify outside monitoring of monetary policy, improve its own incentives to achieve its goals, and increase public understanding of monetary policy. By providing a good analysis and sound motivation for its policy, including a convincing explanation for ex post deviations from the inflation target, it should be able to convince the public of its having both the means and the desire to achieve its goals and in this way increase its credibility, that is, bring inflation expectations in line with the inflation target.

Published minutes and voting records of ECB Council meetings are also important both for outside monitoring whether monetary policy is conducted in a professional way and for giving Council members personal responsibility for their decisions.

A considerable risk, and a likely source of limited legitimacy and credibility, is that Council decisions will be, or will be suspected to be, influenced by strong national interests rather than EMU-wide interests. The spectacle surrounding the appointment of the Executive Board on May 2, 1998, has not contributed to reducing that risk. Thus, suspicions may arise that influential members of the Executive Board or the Council may pursue national rather than

corresponding considerable experience and competence in making conditional forecasts will not participate in the EMU from the start. Some other participating national central banks, due to membership in the ERM and the absence of a crucial role for inflation forecasts under exchange rate targeting, may suffer from considerable lack of competence and experience in making such forecasts. Crash programs to learn the skill and estimate the essential relations may therefore be a wise investment for those NCBs before the end of 1998 . 
European interests. Peer pressure in the Executive Board and the Council may dampen such behavior. However, an explicit inflation target, an explicit use of a conditional inflation forecast as an intermediate target, and a high degree of transparency may be the most effective ways of deterring from such behavior.

As emphasized by von Hagen [107], and as discussed in section 3.3, one role of an intermediate target is to serve as a focal point in the policy discussion, and to define what arguments are admissible in the discussion preceding the policy decision. With an EMU-wide conditional inflation forecast as an intermediate target, the policy discussion naturally focuses on the quality of the forecast, the appropriate horizon, and the position of the forecast relative to the inflation target. Thus, in order to argue that a particular piece of information has implications for the ECB's instrument setting, a member of the Council must provide a convincing argument that this information has an effect on the EMU-wide inflation forecast at the relevant horizon. This requirement should provide considerable discipline to the discussion, and exclude many vacuous cases for instrument changes (or for no change in the instrument).

Within such a framework, it seems appropriate to publish minutes of the Council meetings, where the main arguments for instrument adjustments are summarized. This way, outsiders can monitor the quality and the appropriateness of the discussion, and spot any weak or irrelevant arguments. The argument against publishing minutes is that it may inhibit honest and frank discussions in the Council. In order to avoid that, it seems appropriate to publish summaries of the main arguments and discussion points, without attributing these to individual Council members. ${ }^{51}$ It may also be appropriate to publish voting records, to give individual responsibility to Council members to vote for achieving the EMU inflation target, and to allow the deviations from such voting to be spotted.

However, with regard to voting records, one has to admit the possibility that Council members, in particular the NCB governors, may be subject to considerable pressure in their home countries if published voting records reveal that they have voted against the national interest in favor of the EMU-wide interest. Nevertheless, with a high degree of transparency, clear analyses and explicit inflation forecasts in the ESCB, Council members can easily defend their position with reference to their EMU-wide responsibility. But, in the unfortunate case that the ESCB announces ambiguous targets, provides fuzzy analyses and does not publish explicit inflation forecasts, the resulting ambiguity may arguably make it much more difficult for national governors to defend their position in the face of domestic pressure. Keeping voting records secret may then be the appropriate second-best solution. ${ }^{52}$

One might wish that central banks in general, and the ECB in particular, would choose openness and transparency as the default case, and only resort to secrecy and obfuscation when the arguments for this are strong. Unfortunately, central bank tradition is usually the other way around. In case the ECB should chose secrecy and obfuscation rather than transparency and accountability, the best solution for outside monitoring, as suggested by Tabellini [99], seems to be that the European Parliament and the general public evaluate monetary policy performance as if the ECB had an explicit inflation target. In particular, if the ECB chooses not to publish conditional inflation forecasts, monetary policy can be monitored by comparing reputable outside

\footnotetext{
${ }^{51}$ This is the alternative chosen for the MPC meetings of Bank of England, see [5].

52 However, voting records will most likely still be known by national governments, so this does not shield NCB governors from pressure from governments and finance ministries.
} 
forecasters' forecasts with the inflation target. In any case, independent bodies of experts will play a crucial part in scrutinizing and evaluating ECB monetary policy, and there will certainly be several such bodies publishing competent evaluations.

\subsection{The role of monetary aggregates and money-growth targeting}

What is the role of different monetary aggregates and money-growth targeting in ESCB monetary policy? A rational role for monetary aggregates seems simply to be one set of indicators among many others, whose usefulness depend exclusively on their performance in predicting inflation. Due to the major structural change that the introduction of a new common currency means, and the potential instability of money demand functions during such a change, it is obvious that any such performance is likely to be extremely tenuous, and cannot be assessed and estimated until several years of data have been collected.

In particular, money-growth targeting does not provide any solution to the formidable problem of the uncertainty about the transmission mechanism in the EMU. As emphasized above, and as thoroughly documented in the literature, a most pragmatic application of money-growth targeting, which is best described as inflation targeting in disguise and corresponds to conditional money-growth targeting as discussed in section 4.1, lies behind the success of Bundesbank's monetary policy. The success of this policy is dependent on exploiting the transmission mechanism and, in particular, intentionally deviating from money-growth targets when inflation forecasts reveal that money-growth targets conflict with the inflation target. Inflation targeting in disguise requires the same information about the transmission mechanism as explicit inflation targeting. In practice, the difference seems to be the degree of transparency, that is, that the true circumstances are not explicitly revealed to the public.

Money-growth targeting does not seem to provide a short-cut to credibility for ESCB. As argued above, Bundesbank's credibility is apparently due to its inflation performance, and in spite of its frequent money-growth misses rather than thanks to monetary targeting. The ESCB will, in all likelihood, be obliged to earn its credibility by good inflation performance. And the best inflation performance arises from setting the instrument such that the conditional inflation forecast approaches the inflation target at the appropriate rate.

Indeed, according to the discussion in section 4.1, efficient money-growth targeting is inherently non-transparent, since the frequent revisions of the conditional money-growth target or the frequent misses of an unchanged money-growth target require complex explanations that are difficult to verify. Therefore, the main role of money-growth targeting would seem to be to shroud ESCB monetary policy in an opaque veil, by turning explicit inflation targeting into inflation targeting in disguise.

The alternative kind of money-growth targeting is unconditional money-growth targeting, that is, sticking to a constant money-growth target regardless of the consequences. According to section 4.1, this is transparent but inefficient. As mentioned above, it is possible that the introduction of a common currency may have less drastic effects on the transmission mechanism than one might first think if, as suggested in the conventional wisdom, money is not essential to the transmission mechanism. However, the introduction of a common currency will certainly have drastic effects on the financial structure and on the demand for money. In particular, money demand will naturally be quite unpredictable with such a drastic structural change. 
Furthermore, money demand could also be quite unstable, when economic agents learn their ways in the new environment. Both circumstances imply that any unconditional money-growth targeting, where inflation performance is totally dependent on the predictability and stability of money demand, is likely to cause considerable instability and have dire consequences for EMU price stability.

\section{Summary and conclusions}

The purpose of this paper is to discuss inflation targeting in the context of monetary policy rules. It provides a general conceptual framework for monetary policy rules, clarifies the essential characteristics of inflation targeting, compares inflation targeting to money-growth targeting and nominal-GDP-growth targeting, and draws some conclusions for the monetary policy of the ESCB.

The discussion of the conceptual framework for monetary policy rules starts by recalling the increasingly dominant conventional wisdom about the transmission mechanism of monetary policy, in which the monetary policy instrument, a short nominal interest rate, affects inflation and output via several channels with different lags. This transmission mechanism emphasizes the role of the short nominal and real interest rates. The money stock becomes an endogenous variable which, in the long run, is highly correlated with the price level, but it only plays a minor role in the transmission mechanism, and it has little or no predictive power for inflation beyond other determinants of inflation. The discussion provides definitions of crucial concepts concerning monetary policy rules. Importantly, target variables are variables that enter the loss function to be minimized, rather than, as in some of the literature, variables that enter the reaction function.

In particular, the paper distinguishes between instrument rules and targeting rules, the former being the kind of monetary policy rules mostly discussed in the literature. In practice, however, there appears to be no commitment mechanism by which central banks can be committed to follow a particular instrument rule (or any conceivable commitment mechanism would require such a simple instrument rule that the rule would be manifestly inefficient). They are, at best, guidelines for monetary policy decisions and frames of reference for monetary policy evaluation. Targeting rules, in contrast, provide potential commitment mechanisms, in the sense of commitment to a particular loss function, whereas the actual decision about the instrument, by necessity, remains discretionary.

This framework is consistent with a principal-agent view of monetary policy, where society is seen as the principal and the central bank as its agent, and where society can achieve efficient delegation of monetary policy and improve monetary policy performance by assigning an appropriate loss function to the central bank and creating an institutional framework, with, for instance, instrument independence and appropriate accountability of the central bank.

The unavoidable lags in the effects of monetary policy create a crucial rule for conditional forecasts of target variables. Conditional forecasts can be interpreted as intermediate target variables. Targeting rules for these conditional forecasts can be interpreted as first-order conditions for minimizing the assigned loss functions.

Inflation targeting, as practiced in New Zealand, Canada, U.K., Sweden and Australia is characterized by (1) an explicit quantitative inflation target, (2) an operating procedure that 
can be described as "inflation-forecast targeting", namely the use of an internal conditional forecast of inflation and output as an intermediate target variable, and (3) a high degree of transparency and accountability. The main points argued in the discussion of inflation targeting are: (1) Inflation targeting can be interpreted as a targeting rule, with a relatively explicit loss function to be minimized. Uncontroversially, this loss function also contains concerns about the stability of the real economy, for instance, output variability. That is, it corresponds to "flexible" rather than "strict" inflation targeting. (2) The targeting rule can also be expressed as an intermediate-targeting rule, "inflation-forecast targeting," where the conditional inflation forecast is the intermediate target variable (or where both the conditional inflation forecast and the conditional output-gap forecast are intermediate target variables). (3) Inflation targeting appears to be a commitment to a systematic and rational (that is, optimizing) monetary policy to a greater extent than any other monetary policy regime so far. This is because the operating procedure under inflation targeting, inflation-forecast targeting, can be interpreted as a way of ensuring that first-order conditions for a minimum of the loss function are (approximately) fulfilled. Importantly, the high degree of transparency and accountability associated with inflation targeting allows outsiders to monitor that those first-order conditions are fulfilled and creates stronger incentives for the central bank not to deviate from minimizing the relatively explicit loss function than in other monetary policy regimes.

In the comparison between inflation targeting and money-growth targeting, money-growth targeting is seen as an intermediate-targeting rule to indirectly achieve an inflation target. Since the money-growth target and the inflation target will, unavoidably, frequently conflict, the priority between these two targets is crucial. Money-growth targeting can then, as under Bundesbank's pragmatic policy, be conditional, in the sense of giving priority to the inflation target. It is efficient for achieving the inflation target, but unavoidably nontransparent, since it is really "inflation targeting in disguise" rather than in the open, and the explanations for missing the money-growth target must frequently be complex, ad hoc, and difficult to verify. Alternatively, money-growth targeting can be unconditional, in the sense of giving priority to the money-growth target. It will then be inefficient for stabilizing inflation, but transparent. Hence, money-growth targeting faces the unpleasant choice of being either efficient and nontransparent or inefficient and transparent.

In the comparison between inflation targeting and nominal-GDP-growth targeting, the main difference is that the intermediate loss function under nominal-GDP-growth targeting implies a constant unitary marginal rate of substitution between inflation and real GDP growth, whereas the loss function under inflation targeting involves a variable marginal rate of substitution between inflation and the output gap. There seems to be no good rationale for this constant unitary marginal rate of substitution.

More generally, the difficulties with both money-growth targeting and nominal-GDP targeting are, I believe, due to the fact that neither money nor nominal GDP is an intermediate variable for inflation, in the sense that the monetary policy instrument would affect inflation only via money or nominal GDP. Instead, the transmission mechanism is more complex and involves several channels that do not directly involve either money or nominal GDP. Therefore, money or nominal GDP are not the best predictors of inflation, and stabilizing money growth or nominal GDP growth is not an efficient way of stabilizing inflation (or a weighted sum of inflation and output variability). 
Interestingly, both money-growth targeting and nominal-GDP targeting result in reaction functions where the instrument does not respond to either money growth or nominal GDP but to the different determinants of these.

With regard to the conclusions for the ECB, the paper argues that inflation targeting is the obvious way of achieving the Maastricht treaty's price-stability goal for the ECB, with the inflation target being one percent, the midpoint of the range 0-2 percent for CPI inflation that earlier EMI and more recently the ECB's Executive Board have declared consistent with price stability. A rational role for monetary aggregates is then to be one set of indicators among many, whose usefulness depend solely on their predictive power for future inflation. For obvious reasons, that predictive power is likely to be small or insignificant in the first few years of the EMU, and therefore monetary aggregates are likely to be of little help. The other alternative for ECB is conditional money-growth targeting, which would boil down to being inflation targeting in disguise rather than in the open, and therefore less transparent by focussing the discussion on potentially irrelevant changes in monetary aggregates for inflation.

Several important issues have received little or no attention in the discussion here. Prominent among these are issues of model uncertainty and model-robustness, which are only briefly discussed in section 3.5 and remain urgent areas for further research. Another issue is how to pursue inflation targeting when some shocks are unobservable, something that will be examined in Svensson and Woodford [97]. A relevant issue is the potential drawbacks of too low an inflation target due to nonnegative nominal interest rates and potential downward rigidity of nominal wages. Recent work by Orphanides and Wieland [77] indicates that the former is not a problem for the United States when the inflation target is 2 percent or higher, but that inflation targets below 1 percent would cause output losses. However, if the average real interest rate is assumed to be 2 percent rather than 1 percent, output losses only occur for inflation targets below 0 percent. On the other hand, if the variance of shocks is higher, a higher inflation target is needed to avoid output losses. Recent work by Akerlof, Dickens and Perry [1] indicates that downward nominal rigidity of wages is not a problem for an inflation target of 2 percent or higher, but that an inflation target of 1 percent or lower would cause output losses. For reasons laid out in Gordon [46], I believe that Akerlof, Dickens and Perry's results may be too pessimistic. A further issue is the consequences of any nonlinearity of the Phillips curve, cf. Debelle and Laxton [32] and Isard and Laxton [55]. 


\section{A A consistent conditional forecasts with forward-looking variables}

Constructing the required internal forecasts is, in principle, straightforward within the backwardlooking model used in [91] and [93] (see Rudebusch and Svensson [83] and appendix C), but requires some special considerations in a model with forward-looking expectations of the kind used here. In this appendix, I will show that a consistent inflation forecast can be constructed for a given time path of the instrument in the model (2.1) and (2.2).

For a fixed $t$, we would like to produce a conditional forecast of $X_{t+\tau \mid t}, x_{t+\tau \mid t}$ and $Y_{t+\tau \mid t}$ $(\tau \geq 0)$, conditional upon $X_{t}$, a given instrument path $i_{t+\tau \mid t}(\tau \geq 0)$, and the model (2.1) and (2.2). In order to reduce the number of indices, fix $t=0$, let $X_{0}$ be given, and let $X_{\tau}, x_{\tau}, Y_{\tau}$ and $i_{\tau}$ for $\tau \geq 0$ denote $X_{\tau \mid 0}, x_{\tau \mid 0}, Y_{\tau \mid 0}$ and $i_{\tau \mid 0}$, respectively.

Let the given instrument path be arbitrary for a fixed number, $T$, of periods, $0 \leq \tau \leq T-1$, but restrict it to follow a given reaction function $\hat{f}$ after these periods, that is, for $\tau \geq T$. More precisely, let

$$
i_{\tau}=f_{\tau} X_{\tau}
$$

where the sequence of $T$ row $n_{1}$-vectors, $f_{\tau}, 0 \leq \tau \leq T-1$, is exogenous and arbitrary, and where $f_{\tau}=\hat{f}$ for $\tau \geq T$. Note that since one element, say the first, is unity, for $0 \leq \tau \leq T-1$, the first element of $f_{\tau}, f_{1 \tau}$ is a state-independent component of the instrument. Hence, this formalization admits the constant or time-variable but state-independent instrument paths that central banks sometimes use in their reported conditional forecasts.

Then, for given $X_{0}$ and $f_{\tau}, \tau \geq 0$, we look for $X_{\tau}$ and $x_{\tau}, \tau \geq 0$, that solve

$$
\left[\begin{array}{c}
X_{\tau+1} \\
x_{\tau+1}
\end{array}\right]=G_{\tau}\left[\begin{array}{c}
X_{\tau} \\
x_{\tau}
\end{array}\right]
$$

where

$$
G_{\tau} \equiv A+B F_{\tau}
$$

where $F_{\tau} \equiv\left(f_{\tau}, 0_{1 \times n_{2}}\right)$ denotes the $n$-vector (where $n=n_{1}+n_{2}$ ) formed by inserting $n_{2}$ zeros to the right of $f_{\tau} .^{53}$

From the analysis in section 2, we know the solution for $\tau \geq T$, namely

$$
x_{\tau}=\hat{H} X_{\tau},
$$

where $\hat{H}$ is the solution for the forward-looking variables that result from the reaction function $\hat{f}$. Furthermore, for $\tau \geq T$, the dynamics are given by (2.8)-(2.10). The solution for $0 \leq \tau \leq T-1$ remains to be found. Without restriction, we can write

$$
x_{\tau}=H_{\tau} X_{\tau},
$$

where the $n_{2} \times n_{1}$ matrices $H_{\tau}$ for $0 \leq \tau \leq T-1$, remain to be determined.

\footnotetext{
${ }^{53}$ For the generalization when $B i_{t}$ in $(2.1)$ is replaced by $B^{0} i_{t}+B^{1} i_{t+1 \mid t}$, the matrix $G_{\tau}$ depends on both $f_{\tau}$ and $f_{\tau+1}$ according to

$$
G_{\tau} \equiv\left(I-B^{1} F_{\tau+1}\right)^{-1}\left(A+B^{0} F_{\tau}\right),
$$
}

where the matrix $I-B^{1} F_{\tau+1}$ is assumed to be invertible. 
If $H_{\tau+1}$ is known, we can derive an expression for $H_{\tau}$. Hence, the problem can be found by backward induction. To show this, note that by multiplying the first $n_{1}$ rows in (A.1) and using (A.3) for $\tau+1$, we get

$$
H_{\tau+1} X_{\tau+1}=H_{\tau+1}\left(G_{\tau 11} X_{\tau}+G_{\tau 12} x_{\tau}\right)=x_{\tau+1}=G_{\tau 21} X_{\tau}+G_{\tau 22} x_{\tau},
$$

where

$$
G_{\tau} \equiv\left[\begin{array}{ll}
G_{\tau 11} & G_{\tau 12} \\
G_{\tau 21} & G_{\tau 22}
\end{array}\right]
$$

has been decomposed according to $X_{\tau}$ and $x_{\tau}$. Then, we can solve (A.4) for $x_{\tau}$ in terms of $X_{\tau}$, which results in (A.3), where $H_{\tau}$ is given by

$$
H_{\tau} \equiv\left(G_{\tau 22}-H_{\tau+1} G_{\tau 12}\right)^{-1}\left(H_{\tau+1} G_{\tau 11}-G_{\tau 21}\right)
$$

and we assume that $G_{\tau 22}-H_{\tau+1} G_{\tau 12}$ is invertible. Hence, given $H_{\tau+1}$ we can find $H_{\tau}$ from (A.5). Since we have $H_{T}=\hat{H}$, we can use backward induction to find all $H_{\tau}, 0 \leq \tau \leq T-1$.

It follows that $X_{\tau}, x_{\tau}$ and $Y_{\tau}$ are given by

$$
\begin{aligned}
x_{\tau} & =H_{\tau} X_{\tau} \\
Y_{\tau} & =\left(C_{1}+C_{2} H_{\tau}+D f_{\tau}\right) X_{\tau} \\
X_{\tau+1} & =\left(G_{\tau 11}+G_{\tau 12} H_{\tau}\right) X_{\tau}
\end{aligned}
$$

for $\tau \geq 0$ and $X_{0}$ given.

Thus, consistent conditional forecasts $X_{t+\tau \mid t}, x_{t+\tau \mid t}$ and $Y_{t+\tau \mid t}$ can be constructed for exogenous $f_{\tau}, \tau \geq 0$, as long as there is eventually a shift in policy to a reaction function for which the corresponding matrix $H$ is known. Note that in the end, only the matrix $H$ for $\tau \geq T$ is explicitly used above. Hence, only a consistent assumption about how the forward-looking variables $x_{\tau}$ depend on the vector of state variables $X_{\tau}$ at some given horizon $T$ is actually required. It follows that matrix $H$ need not necessarily correspond to an optimal reaction function for some particular targeting case. The crucial aspect for the internal consistency of the above construction of the conditional forecast is that $H$ is consistent with some reaction function, such that a rational-expectations equilibrium exists at $\tau=T .{ }^{54}$

\section{B A first-order condition for the conditional forecast of target variables}

Let ${ }_{t} Y$ denote the stacked vector $\left(Y_{t}^{\prime}, Y_{t+1 \mid t}^{\prime}, Y_{t+2 \mid t}^{\prime}, \ldots\right)^{\prime}$, let $\tilde{K}$ be the block-diagonal matrix with the diagonal $\left(K, \delta K, \delta^{2} K^{2}, \ldots\right)$, and let the efficient set of $\mathcal{Y}_{t}$ be denoted by the equation ${ }_{t} \mathcal{T}\left({ }_{t} Y\right)=0$, which is assumed differentiable. Then the problem to minimize (2.18) subject to (2.19) can be written

$$
\min \left({ }_{t} Y-{ }_{t} \hat{Y}\right)^{\prime} \tilde{K}\left({ }_{t} Y-{ }_{t} \hat{Y}\right) \text { subject to }{ }_{t} \mathcal{T}\left({ }_{t} Y\right)=0 .
$$

Then, the first-order condition (2.20) can be written

$$
\tilde{K}\left({ }_{t} Y-{ }_{t} \hat{Y}\right)+\mu \frac{\partial_{t} \mathcal{T}\left({ }_{t} Y\right)}{\partial_{t} Y}=0
$$

where $\mu$ is (half) a Lagrange multiplier and $\frac{\partial_{t} \mathcal{I}\left({ }_{t} Y\right)}{\partial_{t} Y}$ is a column vector of stacked derivatives of ${ }_{t} \mathcal{T}\left({ }_{t} Y\right)$ with respect to conditional forecasts of the target variables.

\footnotetext{
${ }^{54}$ For the generalization of $(2.1)$ when $B i_{t}$ is replaced by $B^{0} i_{t}+B^{1} i_{t+1 \mid t}$, we need to use both $H$ and $f$.
} 


\section{A simple closed-economy backward-looking model}

This example of a simple backward-looking model of a closed economy is due to Svensson [91] and [93]. The model has a one-year control lag for the output gap, and a two-year control lag for inflation. The model is also used in Ball [3].

Suppose aggregate supply (the Phillips curve) is given by

$$
\pi_{t+1}=\pi_{t}+\alpha_{y} y_{t}+\varepsilon_{t+1}
$$

where $\alpha_{y}>0, \pi_{t}$ is inflation in year $t, y_{t}$ is the output gap, and $\varepsilon_{t}$ is an iid cost-push shock with zero mean and variance $\sigma_{\varepsilon}^{2} \cdot{ }^{55}$ Let aggregate demand (in terms of the output gap), be given by

$$
y_{t+1}=\tilde{\beta}_{y} y_{t}+\beta_{z} z_{t}-\beta_{r}\left(i_{t}-\pi_{t+1 \mid t}-\bar{r}\right)+\eta_{t+1},
$$

where $\tilde{\beta}_{y} \geq 0, \beta_{r}>0, i_{t}$ is a short nominal interest rate and the central bank's instrument, $\bar{r}$ is the average real interest rate, and $\eta_{t}$ is an iid demand shock with zero mean and variance $\sigma_{\eta}^{2}$. Let $z_{t}$ be an exogenous variable given by

$$
z_{t+1}=\gamma_{z} z_{t}+\theta_{t+1}
$$

where $0 \leq \gamma_{z}<1$ and $\theta_{t}$ is an iid shock with zero mean and variance $\sigma_{\theta}^{2}$.

Note that the one-period-ahead conditional inflation forecast is predetermined,

$$
\pi_{t+1 \mid t}=\pi_{t}+\alpha_{y} y_{t}
$$

This model can be written on state-space form, as in (2.1), where the vector of predetermined variables are given by $X_{t}=\left(\pi_{t}, y_{t}, \pi_{t+1 \mid t}, z_{t}, 1\right)^{\prime}$ and the vector of shocks are $v_{t}=\left(\varepsilon_{t}, \eta_{t}, \varepsilon_{t}+\right.$ $\left.\alpha_{y} \eta_{t}, \theta_{t}, 0\right)^{\prime}$.

The period loss function is

$$
L_{t}=\frac{1}{2}\left[\left(\pi_{t}-\hat{\pi}\right)^{2}+\lambda y_{t}^{2}\right] .
$$

$\lambda \geq 0$ (relative) weight on output-gap stabilization. Thus, the vector of target variables is $Y_{t}=\left(\pi_{t}, y_{t}\right)^{\prime}$, with the target levels $\hat{Y}=(\hat{\pi}, 0)^{\prime}$.

As shown in Svensson [91] and [93], the first-order condition for a minimum of the loss function can be written

$$
\pi_{t+2 \mid t}-\hat{\pi}=-\frac{\alpha_{y} c(\lambda)}{1-c(\lambda)} y_{t+1 \mid t}
$$

where the coefficient $c(\lambda)$ is a function of $\lambda$ and given by

$$
\begin{aligned}
c(\lambda) & \equiv \frac{\lambda}{\lambda+\delta \alpha_{y}^{2} k(\lambda)} \\
k(\lambda) & \equiv \frac{1}{2}\left(1-\frac{\lambda(1-\delta)}{\delta \alpha_{y}^{2}}+\sqrt{\left(1+\frac{\lambda(1-\delta)}{\delta \alpha_{y}^{2}}\right)^{2}+\frac{4 \lambda}{\alpha_{y}^{2}}}\right) \geq 1 .
\end{aligned}
$$

\footnotetext{
${ }^{55}$ In Svensson [91] and [93], aggregate demand is written

$$
y_{t+1}=\beta_{y} y_{t}+\beta_{x} x_{t}-\beta_{r}\left(i_{t}-\pi_{t}\right)+\eta_{t+1},
$$
}

where $\beta_{y}=\tilde{\beta}_{y}+\alpha_{y} \beta_{r}$. This follows from eliminating $\pi_{t+1 \mid t}$ from (C.2) and (C.4) and setting $\bar{r}=0$ 
Furthermore, $c(\lambda)$ fulfills $0 \leq c(\lambda)<1$, with $\frac{\partial c}{\partial \lambda}>0, c(0)=0, c(\infty) \equiv \lim _{\lambda \rightarrow \infty} c(\lambda)=1$.

The one-period-ahead conditional output-gap forecast is given by

$$
y_{t+1 \mid t} \equiv \tilde{\beta}_{y} y_{t}+\beta_{z} z_{t}-\beta_{r}\left(i_{t}-\pi_{t+1 \mid t}-\bar{r}\right),
$$

and the 2-period-ahead conditional inflation forecast fulfills

$$
\begin{aligned}
\pi_{t+2 \mid t} & \equiv \pi_{t+1 \mid t}+\alpha_{y} y_{t+1 \mid t} \\
& =\pi_{t+1 \mid t}+\alpha_{y} \tilde{\beta}_{y} y_{t}+\alpha_{y} \beta_{z} z_{t}-\alpha_{y} \beta_{r}\left(i_{t}-\pi_{t+1 \mid t}-\bar{r}\right) .
\end{aligned}
$$

The first-order condition can also be written

$$
\pi_{t+2 \mid t}-\hat{\pi}=c(\lambda)\left(\pi_{t+1 \mid t}-\hat{\pi}\right)
$$

or

$$
y_{t+1 \mid t}=-\frac{1-c(\lambda)}{\alpha_{y}}\left(\pi_{t+1 \mid t}-\hat{\pi}\right) .
$$

The optimal reaction function can be written as a function of $\pi_{t+1 \mid t}, y_{t}$ and $z_{t}$ (by combining (C.9) and (C.8)),

$$
i_{t}=\bar{r}+\hat{\pi}+\left(1+\frac{1-c(\lambda)}{\alpha_{y} \beta_{r}}\right)\left(\pi_{t+1 \mid t}-\hat{\pi}\right)+\frac{\tilde{\beta}_{y}}{\beta_{r}} y_{t}+\frac{\beta_{z}}{\beta_{r}} z_{t} .
$$

By (C.4) it can also be written as a function of $\pi_{t}, y_{t}$ and $z_{t}$,

$$
i_{t}=\bar{i}+\left(1+\frac{1-c(\lambda)}{\alpha_{y} \beta_{r}}\right)\left(\pi_{t}-\hat{\pi}\right)+\left[\alpha_{y}\left(1+\frac{1-c(\lambda)}{\alpha_{y} \beta_{r}}\right)+\frac{\tilde{\beta}_{y}}{\beta_{r}}\right] y_{t}+\frac{\beta_{z}}{\beta_{r}} z_{t} .
$$

Note that by eliminating $y_{t+1 \mid t}\left(i_{t}\right)$ from (C.6) and (C.7), we can also write the implicit reaction function

$$
i_{t}=\bar{r}+\pi_{t+1 \mid t}+\frac{1-c(\lambda)}{\alpha_{y} \beta_{r} c(\lambda)}\left(\pi_{t+2 \mid t}-\hat{\pi}\right)+\frac{\tilde{\beta}_{y}}{\beta_{r}} y_{t}+\frac{\beta_{z}}{\beta_{r}} z_{t} .
$$

This is an implicit reaction function (hence an equilibrium condition) rather than an (explicit) reaction function, since $\pi_{t+2 \mid t}$ on the right side is endogenous and depends on $i_{t}$. Note that the coefficients of $\pi_{t+1 \mid t}, y_{t}$ and $z_{t}$ are positive, independent of $\lambda$, and hence independent of whether there is strict $(\lambda=0)$ or flexible inflation targeting $(\lambda>0)$. Hence, it is clear that, in general, implicit reaction functions of the form (2.15) or (2.16) are not optimal.

\section{An open-economy forward-looking model}

An example of an open-economy model with forward-looking variables is given in Svensson [96]. The aggregate supply equation (Phillips curve) of the form

$$
\pi_{t+2}=\alpha_{\pi} \pi_{t+1}+\left(1-\alpha_{\pi}\right) \pi_{t+3 \mid t}+\alpha_{y}\left[y_{t+2 \mid t}+\beta_{y}\left(y_{t+1}-y_{t+1 \mid t}\right)\right]+\alpha_{q} q_{t+2 \mid t}+\varepsilon_{t+2} .
$$


Here, for any variable $x, x_{t+\tau \mid t}$ denotes $\mathrm{E}_{t} x_{t+\tau}$, that is, the rational expectation of $x_{t+\tau}$ in period $t+\tau$, conditional on the information available in period $t$. Furthermore, $\pi_{t}$ denotes domestic (log gross) inflation in period $t$. The output gap, $y_{t}$, is defined as

$$
y_{t} \equiv y_{t}^{d}-y_{t}^{n}
$$

where $y_{t}^{d}$ is $(\log )$ aggregate demand and $y_{t}^{n}$ is the $(\log )$ natural output level. The latter is assumed to be exogenous and stochastic and follows

$$
y_{t+1}^{n}=\gamma_{y}^{n} y_{t}^{n}+\eta_{t+1}^{n},
$$

where the coefficient $\gamma_{y}^{n}$ fulfills $0 \leq \gamma_{y}^{n}<1$ and $\eta_{t+1}^{n}$ is a serially uncorrelated zero-mean shock to the natural output level (a "productivity" shock). The variable $q_{t}$ is the (log) real exchange rate, defined as

$$
q_{t} \equiv s_{t}+p_{t}^{*}-p_{t}
$$

where $p_{t}$ is the (log) price level of domestic(ally produced) goods, $p_{t}^{*}$ the (log) foreign price level (measured as deviations from appropriate constant trends), and $s_{t}$ denotes the (log) exchange rate (measured as the deviation from a constant trend, the difference between the domestic inflation target and the mean of foreign inflation; the real exchange rate will be stationary in equilibrium). The term $\varepsilon_{t+2}$ is a zero-mean iid inflation shock (a "cost-push" shock). Thus, there are two distinct "supply" shocks, namely a productivity shock and a cost-push shock. The coefficients $\alpha_{\pi}, \alpha_{y}, \beta_{y}$ and $\alpha_{q}$ are constant and positive; furthermore $\alpha_{\pi}$ and $\beta_{y}$ are smaller than unity. The supply function is derived, with some micro-foundations in Svensson [96], as (roughly) an open-economy extension of Woodford [112] and Rotemberg and Woodford [82]. The term including $q_{t+2 \mid t}$ in (D.1) represents the effect of expected costs of imported intermediate inputs (or resulting wage compensation).

CPI inflation, $\pi_{t}^{c}$, fulfills ${ }^{56}$

$$
\pi_{t}^{c}=(1-\omega) \pi_{t}+\omega \pi_{t}^{f}=\pi_{t}+\omega\left(q_{t}-q_{t-1}\right),
$$

where $\omega, 0 \leq \omega<1$ is the share of imported goods in the CPI. ${ }^{57}$ Here $\pi_{t}^{f}$ denotes domesticcurrency inflation of imported foreign goods, which fulfills

$$
\pi_{t}^{f}=p_{t}^{f}-p_{t-1}^{f}=\pi_{t}^{*}+s_{t}-s_{t-1}=\pi_{t}+q_{t}-q_{t-1}
$$

where

$$
p_{t}^{f}=p_{t}^{*}+s_{t}
$$

is the $(\log )$ domestic-currency price of imported foreign goods, and $\pi_{t}^{*}=p_{t}^{*}-p_{t-1}^{*}$ is foreign inflation. That is, I assume that there is no lag in the pass-through of import costs to domestic prices of imported goods.

\footnotetext{
${ }^{56}$ Since there is no interest-rate component in the CPI, it is best interpreted as CPIX; that is, CPI inflation (and domestic inflation) are exclusive of any credit service costs.

57 The share of imported goods in the CPI is approximately constant for small deviations around a steady state. It is exactly constant if the utility function over domestic and imported goods has a constant elatisticity of substitution equal to unity (that is, is a Cobb-Douglas utility function), as is actually assumed.
} 
Aggregate demand for domestically produced goods is given by the aggregate demand equation (expressed in terms of the output gap, (D.2)),

$$
y_{t+1}=\beta_{y} y_{t}-\beta_{\rho} \rho_{t+1 \mid t}+\beta_{y}^{*} y_{t+1 \mid t}^{*}+\beta_{q} q_{t+1 \mid t}-\left(\gamma_{y}^{n}-\beta_{y}\right) y_{t}^{n}+\eta_{t+1}^{d}-\eta_{t+1}^{n},
$$

where $y_{t}^{*}$ is $(\log )$ foreign output, all coefficients are constant and nonnegative, with $0 \leq \beta_{y}<1$, and $\eta_{t+1}^{d}$ is a zero-mean iid demand shock. The variable $\rho_{t}$ is defined as

$$
\rho_{t} \equiv \sum_{\tau=0}^{\infty} r_{t+\tau \mid t},
$$

where $r_{t}$, the (short domestic-good) real interest rate (measured as the deviation from a constant mean, the natural real interest rate), fulfills

$$
r_{t} \equiv i_{t}-\pi_{t+1 \mid t}
$$

where $i_{t}$ is the (short) nominal interest rate (measured as the deviation from the sum of the inflation target and the natural real interest rate). The nominal interest rate is the instrument of the central bank.

The aggregate demand is predetermined one period in advance. It depends on lagged expectations of accumulated future real interest rates, foreign output and the real exchange rate. The aggregate demand equation is derived, with some microfoundations, and discussed in further detail in Svensson [96]. ${ }^{58}$

The exchange rate fulfills the interest parity condition

$$
i_{t}-i_{t}^{*}=s_{t+1 \mid t}-s_{t}+\varphi_{t}
$$

where $i_{t}^{*}$ is the foreign nominal interest rate and $\varphi_{t}$ is the foreign-exchange risk premium. In order to eliminate the non-stationary exchange rate, I use (D.4) to rewrite this as the real interest parity condition

$$
q_{t+1 \mid t}=q_{t}+i_{t}-\pi_{t+1 \mid t}-i_{t}^{*}+\pi_{t+1 \mid t}^{*}-\varphi_{t} .
$$

I assume that foreign inflation, foreign output and the foreign-exchange risk premium follow stationary univariate $\mathrm{AR}(1)$ processes,

$$
\begin{aligned}
\pi_{t+1}^{*} & =\gamma_{\pi}^{*} \pi_{t}^{*}+\varepsilon_{t+1}^{*} \\
y_{t+1}^{*} & =\gamma_{y}^{*} y_{t}^{*}+\eta_{t+1}^{*} \\
\varphi_{t+1} & =\gamma_{\varphi} \varphi_{t}+\xi_{\varphi, t+1}
\end{aligned}
$$

where the coefficients are nonnegative and less than unity, and the shocks are zero-mean iid. Furthermore, I assume that the foreign interest rate follows a Taylor-type rule, that is, that it is a linear function of foreign inflation and output,

$$
i_{t}^{*}=f_{\pi}^{*} \pi_{t}^{*}+f_{y}^{*} y_{t}^{*}+\xi_{i t}^{*},
$$

${ }^{58}$ There is an obvious similarity to the closed-economy aggregate demand function of Fuhrer and Moore [44], except that a lagged long real coupon-bond rate enters in their function. 
where the coefficients are constant and positive, and $\xi_{i t}^{*}$ is a zero-mean iid shock. These specifications of the exogenous variables are chosen for simplicity; obviously the exogenous variables may be cross-correlated in more general ways without causing any difficulties, and additional variables can be introduced to represent the state of the rest of the world.

In summary, the model consists of the aggregate supply equation, (D.1), the CPI equation, (D.5), the aggregate demand equation, (D.7), the definitions of the sum of current and expected future real interest rates and the real interest rate, (D.8) and (D.9), real interest-rate parity, (D.10), and the equations for the exogenous variables: foreign inflation and output, the foreignexchange risk premium and the foreign interest rate, (D.11)-(D.14).

I assume that the central bank's period loss function is given by

$$
L_{t}=\mu_{\pi}^{c} \pi_{t}^{c 2}+\mu_{\pi} \pi_{t}^{2}+\lambda y_{t}^{2}+\mu_{i} i_{t}^{2}+\nu_{i}\left(i_{t}-i_{t-1}\right)^{2}
$$

where all weights are nonnegative. The first two terms correspond to CPI-inflation targeting and domestic-inflation targeting, respectively. The third term corresponds to output-gap stabilization, the fourth to instrument or nominal interest-rate stabilization, and the fifth to instrument or nominal interest-rate smoothing.

The model can be written in state-space form

$$
\begin{aligned}
{\left[\begin{array}{c}
X_{t+1} \\
x_{t+1 \mid t}
\end{array}\right] } & =A\left[\begin{array}{c}
X_{t} \\
x_{t}
\end{array}\right]+B i_{t}+B^{1} i_{t+1 \mid t}+\left[\begin{array}{c}
v_{t+1} \\
0
\end{array}\right] \\
Y_{t} & =C\left[\begin{array}{c}
X_{t} \\
x_{t}
\end{array}\right]+D i_{t} \\
L_{t} & =Y_{t}^{\prime} K Y_{t}
\end{aligned}
$$

where the predetermined variables, the target variables, the forward-looking variables and the shocks are given by

$$
\begin{aligned}
X_{t} & =\left(\pi_{t}, y_{t}, \pi_{t}^{*}, y_{t}^{*}, i_{t}^{*}, \varphi_{t}, y_{t}^{n}, q_{t-1}, i_{t-1}, \pi_{t+1 \mid t}\right)^{\prime} \\
Y_{t} & =\left(\pi_{t}^{c}, \pi_{t}, y_{t}, i_{t}, i_{t}-i_{t-1}\right)^{\prime} \\
x_{t} & =\left(q_{t}, \rho_{t}, \pi_{t+2 \mid t}\right)^{\prime} \\
v_{t} & =\left(\varepsilon_{t}, \eta_{t}^{d}-\eta_{t}^{n}, \varepsilon_{t}^{*}, \eta_{t}^{*}, f_{\pi}^{*} \varepsilon_{t}^{*}+f_{y}^{*} \eta_{t}^{*}+\xi_{i t}^{*}, \xi_{\varphi t}, \eta_{t}^{n}, 0,0, \alpha_{\pi} \varepsilon_{t}+\alpha_{y} \beta_{y}\left(\eta_{t}^{d}-\eta_{t}^{n}\right)\right)^{\prime},
\end{aligned}
$$

and where $K$ is a diagonal matrix with the diagonal

$$
\left(\mu_{\pi}^{c}, \mu_{\pi}, \lambda, \mu_{i}, \nu_{i}\right)
$$




\section{References}

[1] Akerlof, George A., William T. Dickens and George L. Perry (1996), "The Macroeconomics of Low Inflation," Brookings Papers on Economic Activity 1:1996, 1-76.

[2] Backus, David, and John Driffill (1986), "The Consistency of Optimal Policy in Stochastic Rational Expectations Models," CEPR Discussion Paper No. 124.

[3] Ball, Laurence (1997), "Efficient Rules for Monetary Policy," NBER Working Paper No. 5952 .

[4] Ball, Laurence (1998), "Policy Rules for Open Economies," forthcoming in Taylor [103].

[5] Bank of England (1998), Minutes of the Monetary Policy Committee meeting on 4-5 March 1998, Bank of England.

[6] Bernanke, Ben S., and Mark Gertler (1995), "Inside the Black Box: The Credit Channel of Monetary Policy Tranmission," Journal of Economic Perspectives 9(4), 27-48.

[7] Bernanke, Ben S., Thomas Laubach, Frederic S. Mishkin, and Adam S. Posen (1998), Inflation Targeting: Lessons from the International Experience, manuscript.

[8] Bernanke, Ben S., and Ilian Mihov (1997a), "Measuring Monetary Policy," Working Paper, Princeton University.

[9] Bernanke, Ben S., and Ilian Mihov (1997b), "What Does the Bundesbank Target?" European Economic Review 41, 1025-1054.

[10] Bernanke, Ben S., and Frederic S. Mishkin (1997), "Inflation Targeting: A New Framework for Monetary Policy?" Journal of Economic Perspectives 11, 97-116.

[11] Bernanke, Ben S., and Michael Woodford (1997), "Inflation Forecasts and Monetary Policy," Journal of Money, Credit, and Banking 29, 653-684.

[12] Black, Richard, Vincenzo Cassino, Aaron Drew, Eric Hansen, Benjamin Hunt, David Rose, and Alasdair Scott (1997), "The Forecasting and Policy System: The Core Model," Research Paper No. 43, Reserve Bank of New Zealand, Wellington.

[13] Black, Richard, Tiff Macklem, and David Rose (1997), "On Policy Rules for Price Stability," in Macklem [68].

[14] Blake, Andrew P., and Peter F. Westaway (1996), "Credibility and the Effectiveness of Inflation Targeting Regimes," Manchester School Supplement, 20-50.

[15] Blanchard, Olivier, and Charles M. Kahn, (1980), "The Solution of Linear Difference Models under Rational Expectations," Econometrica 48, 1305-1311.

[16] Blinder, Alan S. (1997), "What Central Bankers Could Learn from Academics - and Vice Versa," Journal of Economic Perspectives 11(2), 3-19. 
[17] Brainard, William (1967), "Uncertainty and the Effectiveness of Policy," American Economic Review 57, Papers and Proceeding, 411-425.

[18] Brayton, Flint, and Peter Tinsley (1996), “Guide to FRB/US: A Macroeconometric Model of the United States, "Federal Reserve Board, FEDS Working Paper 1996-42.

[19] Bryant, Ralph C., Hooper, Peter, and Catherine L. Mann (1993), "Evaluating Policy Regimes and Analytical Models: Background and Project Summary," in Ralph C. Bryant, Peter Hooper and Catherine L. Mann, eds., Evaluating Policy Regimes: New Research in Empirical Macroeconomics, The Brookings Institution, Washington D.C.

[20] Cecchetti, Stephen G. (1995), "Inflation Indicators and Inflation Policy," NBER Macroeconomics Annual 10, 189-219.

[21] Cecchetti, Stephen G. (1997), "Central Bank Policy Rules: Conceptual Issues and Practical Considerations," Working Paper, Federal Reserve Bank of New York.

[22] Christiano, Lawrence J., Martin Eichenbaum, and Charles Evans (1996), "The Effects of Monetary Policy Shocks: Evidence from the Flow of Funds," Review of Economics and Statistics 78, 16-34.

[23] Clarida, Richard, Jordi Gali, and Mark Gertler (1997a), "Monetary Policy Rules and Macroeconomic Stability: Evidence and Some Theory," Working Paper, May 1997.

[24] Clarida, Richard, Jordi Gali and Mark Gertler (1997b), "Monetary Policy Rules in Practice: Some International Evidence," Working Paper, June 1997.

[25] Clarida, Richard, Jordi Gali and Mark Gertler (1997c), "The Science of Monetary Policy," Working Paper.

[26] Clarida, Richard, and Mark Gertler (1997), "How the Bundesbank Conducts Monetary Policy," in Romer, Christina, and David Romer, eds., Reducing Inflation: Motivation and Strategy, Chicago University Press.

[27] Clark, Peter, Douglas Laxton, and David Rose (1996), "Asymmetry in the U.S. OutputInflation Nexus," IMF Staff Papers 43, 216-251.

[28] Coletti, Donald, Benjamin Hunt, David Rose and Robert Tetlow (1996), "Bank of Canada's New Quarterly Projection Model. Part 3, The Dynamic Model: QPM," Technical Report No. 75, Bank of Canada, Ottawa.

[29] Cukierman, Alex, and Allan H. Meltzer (1986), "A Theory of Ambiguity, Credibility, and Inflation under Discretion and Asymmetric Information," Econometrica 54, 1099-1128.

[30] Currie, David, and Paul Levine (1993), Rules, Reputation and Macroeconomic Policy Coordination, Cambridge University Press, Cambridge.

[31] Cushman, David O., and Tao Zha (1997), "Identifying Monetary Policy in a Small Open Economy under Flexible Exchange Rates," Journal of Monetary Economics 39, 433-448. 
[32] Debelle, Guy, and Douglas Laxton (1997), "Is the Phillips Curve Really a Curve? Some Evidence for Canada, the United Kingdom, and the United States," Staff Papers 44, 249-282.

[33] de Brouwer, Gordon, and James O'Regan (1997), "Evaluating Simple Monetary-policy Rules for Australia," in Lowe [67].

[34] Deutsche Bundesbank (1996), Annual Report 1995, Deutsche Bundesbank.

[35] Dennis, Richard (1998), "Instability Under Nominal GDP Targeting: The Role of Expectations," Working Paper, Australia National University.

[36] European Monetary Institute (1997), The Single Monetary Policy in Stage Three: Elements of the Monetary Policy Strategy in the ESCB, European Monetary Institute.

[37] European Parliament (1998), Hearing of candidates to the Board of the ECB, 7 and 8 May 1988, Committee on Economic and Monetary Affairs and Industrial Policy, European Parliament.

[38] Faust, Jon W. (1996), "Whom Can We Trust to Run the Fed? Theoretical Support for the Founders' Views," Journal of Monetary Economics 37, 267-283.

[39] Faust, Jon W., and Lars E.O. Svensson (1998), "Credibility and Transparency: Monetary Policy with Unobservable Goals," Working Paper.

[40] Federal Reserve Bank of Kansas City (1996), Achieving Price Stability, Federal Reserve Bank of Kansas City.

[41] Fischer, Stanley (1996), "Why Are Central Banks Pursuing Long-Run Price Stability?" in Federal Reserve Bank of Kansas City [40].

[42] Freedman, Charles (1996), "What Operating Procedures Should Be Adopted to Maintain Price Stability?" in Federal Reserve Bank of Kansas City [40].

[43] Fuhrer, Jeffrey C., and Brian F. Madigan (1997), "Monetary Policy When Interest Rates Are Bounded at Zero," Review of Economics and Statistics 79, 573-585.

[44] Fuhrer, Jeffrey C., and George R. Moore (1995), "Monetary Policy Trade-Offs and the Correlation between Nominal Interest Rates and Real Output," American Economic Review $85,219-239$

[45] Goodfriend, Marvin, and Roberg G. King (1997), "The New Neoclassical Synthesis and the Role of Monetary Policy," NBER Macroeconomics Annual 1997, 231-283.

[46] Gordon, Robert J. (1996), "Comments and Discussion," Brookings Papers on Economic Activity 1:1996, 60-66.

[47] Haldane, Andrew G., ed. (1995), Targeting Inflation, Bank of England, London.

[48] Haldane, Andrew G. (1997a), "Designing Inflation Targets," in Philip Lowe, ed., Monetary Policy and Inflation Targeting, Reserve Bank of Australia, Sidney, 74-112. 
[49] Haldane, Andrew G., ed. (1997b), "On Inflation-Targeting in the United Kingdom," Scottish Journal of Political Economy, forthcoming.

[50] Haldane, Andrew G., and Nicoletta Batini (1998), "Forward-Looking Rules for Monetary Policy," in Taylor [103], forthcoming.

[51] Hallman, Jeffrey J., Richard D. Porter, and David H. Small (1991), "Is the Price Level Tied to the M2 Monetary Aggregate in the Long Run?," American Economic Review 81, 841-858.

[52] Hansen, Lars Peter, and Thomas J. Sargent (1998), "Alternative Representation of Discounted Robust Linear Quadratic Control," Working Paper.

[53] Henderson, Dale W., and Warwick J. McKibbin (1993), "A Comparison of Some Basic Monetary Policy Regimes for Open Economies: Implications of Different Degrees of Instrument Adjustment and Wage Persistence," Carnegie-Rochester Conference Series on Public Policy 39, 221-317.

[54] Henderson, Dale W., and Warwick J. McKibbin (1993), "An Assessment of Some Basic Monetary Policy Regime Pairs: Analytical and Simulation Results from Simple MultiRegion Macroeconomic Models," in Bryant, Hooper and Mann [19]

[55] Isard, Peter, and Douglas Laxton (1996), "Strategic Choice in Phillips Curve Specification: What if Bob Gordon is Wrong?" Working Paper.

[56] Issing, Otmar (1994), "Die Geldmengenstrategie der Deutschen Bundesbank," Deutsche Bundesbank, Auszüge aus Presseartikeln 91, December 9, 1-11.

[57] Judd, John P., and Brian Motley (1992), "Controlling Inflation with an Interest Rate Instrument," Economic Review, Federal Reserve Bank of San Francisco, No. 3, 3-22.

[58] King, Mervyn A. (1994), "Monetary Policy in the UK," Fiscal Studies 15, No. 3, 109-128.

[59] King, Mervin A. (1996), "How Should Central Banks Reduce Inflation?-Conceptual Issues," in Federal Reserve Bank of Kansas City [40].

[60] King, Mervyn A. (1997), "Changes in UK Monetary Policy: Rules and Discretion in Practice," Journal of Monetary Economics 39, 81-97.

[61] King, Robert G., and Mark W. Watson (1995), "The Solution of Singular Difference Systems Under Rational Expectations," Working Paper.

[62] King, Robert G., and Alexander L. Wolman (1996), "Inflation Targeting in a St. Louis Model of the 21st Century," NBER Working Paper No 5507.

[63] Klein, Paul (1997), "Using the Generalized Schur Form to Solve a System of Linear Expectational Difference Equations," Working Paper, Institute for International Economic Studies. 
[64] Kohn, Donald L. (1996), "Commentary: What Operating Procedures Should Be Adopted to Maintain Price Stability?" in Federal Reserve Bank of Kansas City [40].

[65] Leiderman, Leonardo, and Lars E.O. Svensson, eds. (1995), Inflation Targets, Centre of Econonomic Policy Research, London.

[66] Levin, Andrew, Volker Wieland and John C. Williams (1998), "Robustness of Simple Monetary Policy Rules under Model Uncertainty," in Taylor [103], forthcoming.

[67] Lowe, Philip, ed., (1997), Monetary Policy and Inflation Targeting, Reserve Bank of Australia.

[68] Macklem, Tiff, ed. (1998), Price Stability, Inflation Targets, and Monetary Policy, Bank of Canada.

[69] McCallum, Bennett T. (1988), "Robustness Properties of a Rule for Monetary Policy," Carnegie-Rochester Conference Series on Public Policy 29, 173-204.

[70] McCallum, Bennett T. (1997a), "Issues in the Design of Monetary Policy Rules," NBER Working Paper No. 6016.

[71] McCallum, Bennett T. (1997b), "The Alleged Instability of Nominal Income Targeting." NBER Working Paper No. 6291.

[72] McCallum, Bennett T., and Edward Nelson (1997), "An Optimizing IS-LM Specification for Monetary Policy and Business Cycle Analysis," NBER Working Paper No. 5875.

[73] McCallum, Bennett T., and Edward Nelson (1998), "Nominal Income Targeting in an Open-Economy Optimizing Model," prepared for Sveriges Riksbank-IIES Conference on Monetary Policy Rules, Stockholm, June 12-13, 1998.

[74] Merriam-Webster (1988), Webster's Ninth New Collegiate Dictionary, Merriam-Webster.

[75] Mishkin, Frederic S. (1995), "Symposium on the Monetary Transmission Mechanism," Journal of Economic Perspectives 9(4), 3-10.

[76] Neumann, Manfred (1997), "Monetary Targeting in Germany," in Kuroda, Iwao, ed., Towards More Effective Monetary Policy, St. Martin's Press, New York.

[77] Orphanides, Athanasios, and Volker Wieland (1998), "Price Stability and Monetary Policy Effectiveness when Nominal Interest Rates Are Bounded at Zero," Working Paper, Federal Reserve Board.

[78] Oudiz, Gilles, and Jeffrey Sachs (1985), "International Policy Coordination in Dynamic Macroeconomic Models," in William H. Buiter and Richard C. Marston, eds., International Economic Policy Coordination, Cambridge University Press, Cambridge.

[79] Reserve Bank of New Zealand (1997), Monetary Policy Statement, June 1997, Wellington. 
[80] Reifschneider, David L., David J. Stockton and David W. Wilcox (1997), "Econometric Models and the Monetary Policy Process," Carnegie-Rochester Conference Series on Public Policy 47, 1-37.

[81] Rogoff, Kenneth (1985), "The Optimal Degree of Commitment to an Intermediate Monetary Target," Quarterly Journal of Economics 100, 1169-1190.

[82] Rotemberg, Julio J., and Michael Woodford (1997), "An Optimization-Based Econometric Framework for the Evaluation of Monetary Policy," NBER Macroeconomics Annual 1997, 297-346.

[83] Rudebusch, Glenn, and Lars E.O. Svensson (1998), "Policy Rules for Inflation Targeting," in Taylor [103], forthcoming.

[84] Rudebusch, Glenn D., and Carl E. Walsh (1998), "U.S. Inflation Targeting: Pro and Con," FRBSF Economics Letters 98-18.

[85] Sargent, Thomas J. (1998a), The Conquest of American Inflation, Marshall Lecture, October 1996, Cambridge University.

[86] Sargent, Thomas J. (1998b), "Discussion of 'Policy Rules for Open Economies' by Laurence Ball", in Taylor [103], forthcoming.

[87] Sims, Christopher A. (1996), "Solving Linear Rational Expectations Models," manuscript.

[88] Stock, James H. (1998), "Making Policies Robust to Model Uncertainty: Comment on 'Policy Rules for Inflation Targeting' by Glenn Rudebusch and Lars E.O. Svensson," in Taylor [103], forthcoming.

[89] Svensson, Lars E.O. (1994b), "Why Exchange Rate Bands? Monetary Independence in Spite of Fixed Exchange rates," Journal of Monetary Economics 33, 157-199.

[90] Svensson, Lars E.O. (1996), "Commentary: How Should Monetary Policy Respond to Shocks while Maintaining Long-Run Price Stability? - Conceptual Issues," in Federal Reserve Bank of Kansas City [40].

[91] Svensson, Lars E.O. (1997a), "Inflation Forecast Targeting: Implementing and Monitoring Inflation Targets," European Economic Review 41, 1111-1146.

[92] Svensson, Lars E.O. (1997b), "Inflation Targeting in an Open Economy: Strict vs. Inflation Targeting," Public Lecture at Victoria University of Wellington, Reserve Bank of New Zealand Discussion Paper G 97/8.

[93] Svensson, Lars E.O. (1997c), "Inflation Targeting: Some Extensions," NBER Working Paper No. 5962.

[94] Svensson, Lars E.O. (1998a), "Better to Respond to Determinants of Targets than to Targets Themselves," in preparation. 
[95] Svensson, Lars E.O. (1998b), "Does the $P^{*}$ Model Provide Any Rationale for Monetary Targeting?" Working Paper.

[96] Svensson, Lars E.O. (1998c), "Open-Economy Inflation Targeting," NBER Working Paper No. 6545 .

[97] Svensson, Lars E.O., and Michael Woodford (1998), "Indicators and Forecasts in Inflation Targeting," in preparation.

[98] Sveriges Riksbank (1997), Inflation Report, September 1997, Sveriges Riksbank.

[99] Tabellini, Guido (1998), "Inflation Targeting and the Accountability of the European Central Bank," statement prepared for a hearing organized by the Subcommitte on Monetary Affairs, European Parliament, January 6, 1998.

[100] Taylor, John B. (1993), "Discretion versus Policy Rules in Practice," Carnegie-Rochester Conference Series on Public Policy 39, 195-214.

[101] Taylor, John B. (1996), "How Should Monetary Policy Respond to Shocks while Maintaining Log-Run Price Stability - Conceptual Issues," in Federal Reserve Bank of Kansas City [40].

[102] Taylor, John B. (1998a), "A Historical Analysis of Monetary Policy Rules," in Taylor [103], forthcoming.

[103] Taylor, John B., ed. (1998b), Monetary Policy Rules, Chicago University Press, forthcoming.

[104] Taylor, John B., ed. (1998c), "The Robustness and Efficiency of Monetary Policy Rules as Guidelines for Interest Rate Setting by the European Central Bank," prepared for Sveriges Riksbank-IIES Conference on Monetary Policy Rules, Stockholm, June 12-13, 1998.

[105] Tödter, Karl-Heinz, and Gerhard Ziebarth (1997), "Price Stability vs. Low Inflation in Germany: An Analysis of Costs and Benefits," NBER Working Paper No. 6150.

[106] von Hagen, Jürgen (1995), "Inflation and Monetary Targeting in Germany," in Leiderman and Svensson [65].

[107] von Hagen, Jürgen (1998), "Money Growth Targeting,” prepared Sveriges Riksbank-IIES Conference on Monetary Policy Rules, Stockholm, June 12-13, 1998.

[108] Walsh, Carl E. (1997), Monetary Theory and Policy, manuscript.

[109] Wieland, Volker (1996), "Monetary Policy, Parameter Uncertainty and Optimal Learning," Working Paper, Federal Reserve Board.

[110] Wieland, Volker (1998), "Monetary Policy and Uncertainty about the Natural Unemployment Rate," Finance and Economics Discussion Paper No. 22, Federal Reserve Board. 
[111] Woodford, Michael (1994), "Nonstandard Indicators for Monetary Policy: Can Their Usefulness Be Judged from Forecasting Regressions?" in Gregory N. Mankiw, ed., Monetary Policy, University of Chicago Press, Chicago.

[112] Woodford, Michael (1996), "Control of the Public Debt: A Requirement for Price Stability," NBER Working Paper No. 5684.

[113] Yun, Tack (1966), "Nominal Price Rigidity, Money Supply Endogeneity, and Business Cycles," Journal of Monetary Economics 37, 345-370. 